\title{
BARGAINING AND DISTRIBUTION OF POWER IN THE EU's CONCILIATION COMMITTEE
}

\author{
STEFAN NAPEL \\ MIKA WIDGRÉN \\ CESIFo Working PAPER No. 1029 \\ CATEgory 2: Public Choice \\ SEPTEMBER 2003 \\ An electronic version of the paper may be downloaded \\ - from the SSRN website: \\ - from the CESifo website: \\ www.SSRN.com \\ www.CESifo.de
}




\title{
BARGAINING AND DISTRIBUTION OF POWER IN THE EU's CONCILIATION COMMITTEE
}

\begin{abstract}
The European Union (EU) has moved towards bicameralism, making the codecision procedure its most important mechanism for decision making. To gauge if European Parliament (EP) and Council of Ministers (CM) are equally powerful 'codecision makers', understanding of the final stage of the procedure - bargaining in the Conciliation Committee is crucial. Here, EP and CM are assumed to have spatial preferences determined by their respective internal decision mechanisms. Applying bargaining theory to predict interinstitutional agreements in the Conciliation Committee, it turns out that although institutionally the Council and the Parliament are seemingly in a symmetric position, CM has significantly greater influence on EU legislation.
\end{abstract}

JEL Code: C70, C78, D70, D72.

Keywords: European Union codecision procedure, Conciliation Committee, bargaining, spatial voting, decision procedures

\author{
Stefan Napel \\ Boston University \\ Department of Economics \\ 270 Bay State Road \\ Boston MA, 02215 \\ U.S.A. \\ napel@bu.edu
}

\author{
Mika Widgrén \\ Turku School of Economics \\ Rehtorinpellonkatu 3 \\ 20500 Turku \\ Finland \\ mika.widgren@tukkk.fi
}

This research has been supported by the Yrjö Jahnsson Foundation. S. Napel gratefully acknowledges financial support from the German Academic Exchange Service (DAAD). The authors have benefitted from comments on earlier versions presented at Boston University, 14th Summer Festival on Game Theory at Stony Brook, and 15th Italian Meeting on Game Theory and Applications in Urbino. 


\section{Introduction}

Bargaining between European Parliament (EP) and Council of Ministers (CM) in the Conciliation Committee represents the final chance to implement a change to the status quo under the European Union's codecision procedure. The bargaining outcome that EP, CM, and also the European Commission $(\mathrm{EC})^{1}$ expect to result from invoking the Conciliation Committee plays a crucial role at earlier stages of the procedure. Using backward induction it can be concluded that it is indeed the determinant of any codecision agreement if EP, $\mathrm{CM}$, and EC act strategically.

Analysis of the Conciliation Committee and the distribution of power in it is therefore precondition for analysis of the codecision procedure as such. Consequently, several authors have devoted their attention to the Conciliation Committee including Steunenberg and Dimitrova (1999), Crombez (1997, 2000), Tsebelis and Garrett (2000), and Steunenberg and Selck (2002). Their mostly qualitative assessments of who shapes the compromises reached by EP and CM - and hence the distribution of power between these two players diverge.

Crombez regards EP as the agenda setter in the Conciliation Committee but concludes nevertheless that both EP and CM "genuinely codecide which policy to implement" (1997, p. 113). His analysis does not discriminate much between the Maastricht and Amsterdam versions of codecision, ${ }^{2}$ which according to Steunenberg and Selck (2002), however, has no significant consequences (based on the methodology of Steuenberg et al., 1999). Tsebelis and Garrett (2000) focus on the Amsterdam version and argue that the EU has moved towards bicameralism. Inspired by formal bargaining models, they find no reason to suggest that either CM or EP is favored by the procedure, so that both can be expected to have the same influence.

In contrast, Steunenberg and Dimitrova (1999) observe an advantage to CM, in particular the member country holding its presidency, in a model that assumes the Council president to make a take-it-or-leave-it offer to EP. The latter assumption builds an asymmetry into the model - making greater power for CM a non-surprising consequence - which is controversial not only because of the commitment problems associated with such offers.

However, we find that Steunenberg and Dimitrova's conclusion of a significant advantage for CM remains valid also for symmetric bicameral bargaining, as assumed by Garrett and Tsebelis. Key to this conclusion is the assumption that the representatives of the two chambers have preferences defined by aggregating unidimensional single-peaked preferences of individual members of EP and CM using the institutions' respective voting rules. Intrainstitutional majority rules are an important factor in inter-institutional bargaining, which

\footnotetext{
${ }^{1}$ The Commission only acts as a facilitator in the Conciliation Committee but is an essential player in the preceding stages of the decision process - in particular, it initiates the codecision procedure.

${ }^{2}$ The original version of codecision, laid out in the Maastricht Treaty in 1992, was revised by the Treaty of Amsterdam in 1997 specifically to make the procedure more symmetric, see e. g. the comments by Tsebelis and Garrett (2000), Tsebelis and Money (1997), Crombez (2000), Crombez et al. (2000), and Garrett et al. (2001). Steunenberg (1994, 2000), Garrett (1995), and Crombez (1997) analyze the pre-Amsterdam version.
} 
the literature has largely neglected.

This paper aims at a comprehensive quantitative analysis of the bargaining process in the Conciliation Committee. It assumes strategic players with spatial preferences characterized by individual ideal points in a Euclidian policy space, and carries out a step-by-step analysis of the two canonical models of bilateral bargaining - cooperative Nash bargaining and noncooperative Rubinstein bargaining - with variations. We do not argue that either Nash or Rubinstein bargaining is the most appropriate model to explain or predict agreements in the EU's Conciliation Committee. Still, the increasing relevance of codecision and the central strategic role of bargaining between EP and CM in it in our view warrant a detailed consideration of the non-obvious implications of these standard bargaining models. $^{3}$

Our first - only at first sight counter-intuitive - observation is that compromises reached by EP and CM will typically not be close to or even exactly in the middle of both decision bodies' ideal policy points. Instead, there is a very robust bias of the bargaining outcome in favor of the player with smaller distance between its ideal point and the status quo, i. e. an important status quo bias. For illustration, suppose that utility of EP's and CM's respective representatives decreases linearly in the distance between each player's unidimensional ideal point and status quo. Then, the symmetric Nash bargaining solution predicts an agreement exactly on the ideal point of the player with smaller distance to status quo if there exists any mutually beneficial policy change at all. Predictions are less extreme for strictly concave utility and Rubinstein bargaining with non-negligible impatience, but significant status quo bias persists.

Status quo bias is compatible with symmetric power or average influence on the bargaining outcome only if $\mathrm{EP}$ and $\mathrm{CM}$ are equally likely to be the more enthusiastic one about changing the status quo. A priori, i. e. assuming identical preference distributions for the members of EP and CM, this is not the case: It is shown that CM's qualified majority requirement makes the distribution of its collective ideal point - corresponding to the distribution of the ideal point of its pivotal member - pronouncedly skewed in contrast to an almost symmetric distribution implied by EP's simple majority rule. This implies that CM is far more often the player closer to the status quo and, by bargaining's status quo bias, to define the compromise reached in the Conciliation Committee. Measuring a player's power as the sensitivity of the collective decision to its preferences (see Napel and Widgrén, 2002), CM's a priori power turns out to exceed that of EP by an order of magnitude.

The remainder of the paper is organized as follows: Section 2 discusses the representation of preferences of EP and CM members in a bargaining context. Assuming that spatial preferences with von Neumann-Morgenstern representations exist also for EP and CM in aggregate, Section 3 concerns the cooperative Nash bargaining solution, explicitly deriving the Nash bargain agreed upon by EP and CM in case of linear utility (risk neutrality). The key finding of this example is pronounced bias towards the ideal point which is closer to

\footnotetext{
${ }^{3}$ For a game-theoretic investigation of the codecision procedure as such, in which the Conciliation Committee is but the final stage, see Napel and Widgrén (2003).
} 
the status quo. This is generalized to arbitrary single-peaked spatial preferences. Section 4 analyzes noncooperative models of alternating offers bargaining, first looking at ones with an exogenously fixed number of stages and then Rubinstein's infinite horizon model. These models confirm earlier conclusions. Section 5 comments on bargaining models which assume only boundedly rational agents. Section 6 then deals with the implications of status quo bias for inter-institutional power and average influence of EP and CM on European Union policies. Section 7 summarizes our conclusions and discusses possible extensions of the analysis.

\section{Spatial Preferences}

It is common in models of political decision-making to assume that the preferences of political actors are single-peaked and can be characterized by a bliss point or ideal point in a multi-dimensional space $X \subseteq \mathbb{R}^{n}$ together with a metric $d$ on $X$ such that the further an agent's ideal point $\lambda$ is away from a policy $x \in X$, the less satisfied he or she is by $x{ }^{4}$ Such preferences can be represented by any utility function $u$ which is decreasing in distance $d(\lambda, x)$ between $\lambda$ and $x$, where $d$ can be standard Euclidian distance or any other metric. Any utility function $\tilde{u}$ that results from a strictly increasing transformation of $u$ represents the considered player's preferences just as well (see Fig. 1 for an illustration with unidimensional $X$ ). In other words: standard spatial preferences are ordinal and nothing can be said either about how much a player $i$ with ideal point $\lambda_{i}$ suffers from policy $x$ compared to a player $j$ with ideal point $\lambda_{j}$ nor, which is crucial in the context of bargaining, which probability of having ideal point $\lambda_{i}$ implemented instead of some point $y$ would make player $i$ prefer this 'gamble' or lottery to the safe alternative $x$.

So, more information about preferences than in a simple median voting world is needed when political actors are considered to bargain. Bargaining agents face the risk of failing to reach an agreement if they do not give in to their opponent's most preferred alternative right away. Moreover, bargaining is usually conducted in a time and resource-consuming manner. Having policy $x$ implemented today must therefore be compared, for example, with experiencing the status quo $q \in X$ for another bargaining period and then implementing policy $y$. Meaningful models of bargaining require a specification of either agents' risk preference or time preference or both.

Representing spatial preferences in an $n$-dimensional space by simple functional forms like

$$
u(\lambda, x)=-\sum_{k=1}^{n}\left(\lambda_{k}-x_{k}\right)^{2}
$$

or

$$
\tilde{u}(\lambda, x)=-\sum_{k=1}^{n}\left|\lambda_{k}-x_{k}\right|
$$

\footnotetext{
${ }^{4}$ The assumption that smaller distance is always better is very restrictive. It implies that utility must be symmetric in $\lambda-x$ space, i. e. players have concentric indifference curves and do care about the distance between $\lambda$ and $x$, but not about the latter's position.
} 


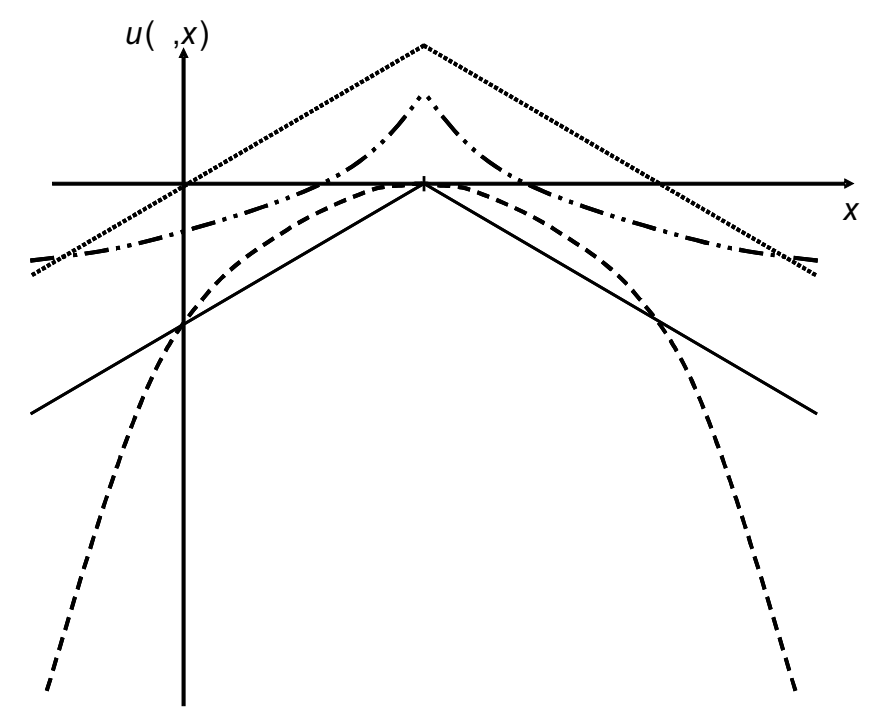

Figure 1: Alternative utility representation of spatial preferences with ideal point $\lambda$

is possible also in the context of bargaining. However, above functions $u$ and $\tilde{u}$ are no longer equivalent when interpreted as cardinal utility functions used to evaluate risky choices by taking expectations (von Neumann-Morgenstern expected utility) or to which a time discount factor $\delta \in(0,1)$ can be applied, i. e. using $U(\lambda, x, t)=\delta^{t} \cdot u(\lambda, x)$ in order to compare possible agreements at different points in time. This has to be remembered when spatial preferences are used in a bargaining context.

\section{$3 \quad$ Nash Bargaining with Spatial Preferences}

A grossly simplifying assumption in the analysis of negotiations between European Parliament (EP) and the Council of Ministers (CM) is that - at least during their dealings in the Conciliation Committee - both are unitary actors with determinate ideal points. This assumes that there are real or virtual representatives of both EP and CM who possess spatial preferences just like individual members of both institutions are assumed to do (see Section 2). The ideal points of these representatives, denoted by $\pi$ for the Parliament and $\mu$ for Ministers in the following, are naturally given by the ideal points of the respective institution's median or pivotal members on a particular issue, i. e. for a unidimensional policy space $X \subseteq \mathbb{R}$. For higher dimensions, the assumption of a well-defined collective preference is - despite the strong restrictions imposed on individual preferences - not innocuous at all. For the sake of simplicity, it will nevertheless be made. ${ }^{5}$ Until Section 6 ,

\footnotetext{
${ }^{5}$ See Bade (2002) for an innovative analysis of multidimensional electoral competition. Under the assumption that two competing parties select their platform under uncertainty (rather than only risk) about voters' preferences, she proves existence of an equilibrium for many multidimensional cases. Moreover, each party announces the respective median position in each separate dimension in equilibrium. This may explain the importance of single-issue decisions in practice and justify unidimensional models.
} 


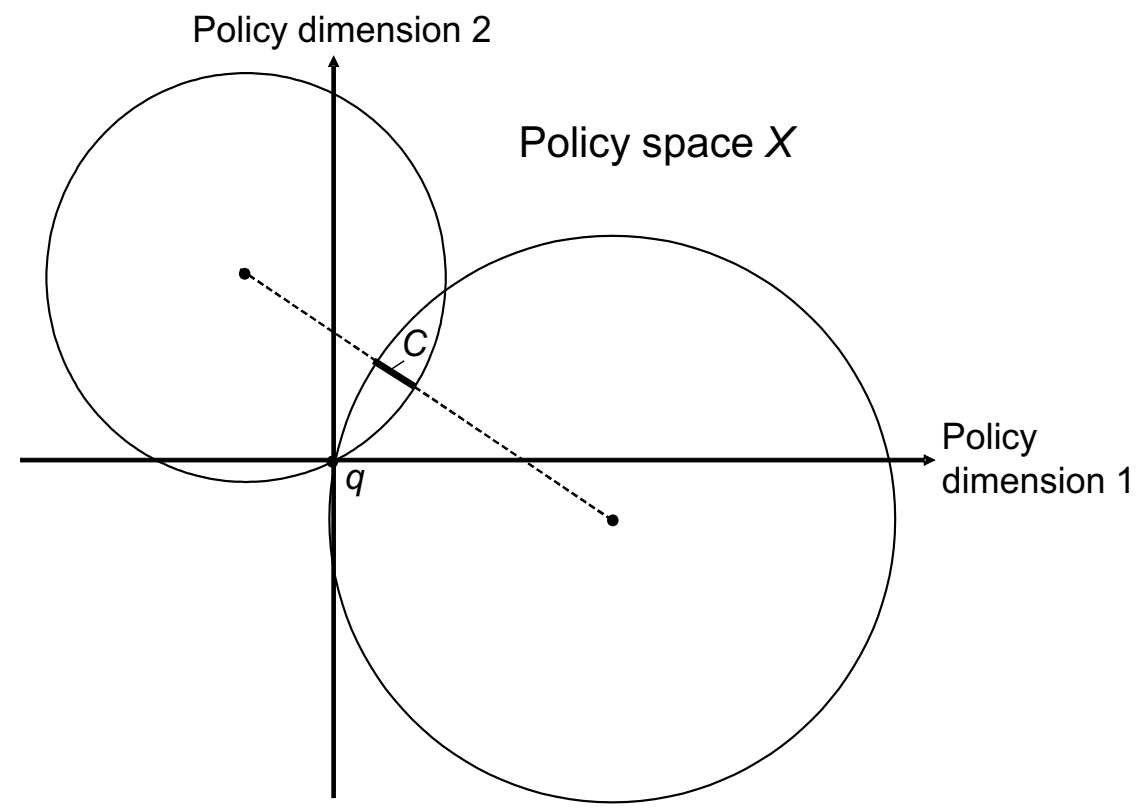

Figure 2: Contract curve $C$ in case of a two-dimensional policy space

EP's and CM's ideal points $\pi$ and $\mu$ are assumed to be exogenously given.

Rational players will seek to agree on some Pareto-efficient policy outcome $\hat{x} \in X$, corresponding to utility levels $\left(\hat{u}_{\pi}, \hat{u}_{\mu}\right)$ for EP and CM, respectively, none of which can be raised without lowering the other one. The subset of Pareto-efficient policies which are considered as least as good as the status quo by both players is the contract curve introduced by Edgeworth (1881). For spatial preferences, the contract curve is the segment of the line connecting $\pi$ and $\mu$ which lies within the intersection of the two balls (lines or discs for $n=1,2)$ with centers $\pi$ and $\mu$ and radii $d(\pi, q)$ and $d(\mu, q)$, respectively, where $q \in X$ refers to the status quo (see Fig. 2). Bilateral bargaining over multidimensional policy issues under complete information therefore amounts to unidimensional bargaining. The contract curve $C$ is non-empty, i. e. there are 'gains from trade' between EP and CM, unless the line connecting $\pi$ and $\mu$ passes through $q$, i. e. unless EP and CM have exactly opposite positions.

Nash (1950) studied the bargaining problem in a still more abstract way. In particular, his analysis did neither presuppose nor take into account any particular context of bargaining such as bilateral trade or agreement on some policy. Rather, he identified a bargain entirely by looking at players' von Neumann-Morgenstern utility levels, i. e. their (commonly known) subjective evaluations of the underlying bargaining situation. Any point $x$ in policy space $X$ can be mapped to the particular utility pair $\left(u_{\pi}(x), u_{\mu}(x)\right)$ that reflects players' preferences for it. This defines the bargaining set $U$ of all feasible utility combinations. Utility pair $u^{q}=\left(u_{\pi}^{q}, \bar{u}_{\mu}^{q}\right) \equiv\left(u_{\pi}(q), u_{\mu}(q)\right)$ summarizes players' evaluation of the status quo situation and has an important effect on negotiations.

Nash took $U$ and $u^{q} \in U$ as a sufficient description of any bilateral bargaining situation, assuming two perfectly rational players that cannot fool or trick each other. He searched for 
a mapping $F$ from arbitrary bargaining problems $\left\langle U, u^{q}\right\rangle^{6}$ to a unique element $F\left(U, u^{q}\right) \in U$ which satisfies "several properties that it would seem natural for the solution to have" (Nash 1953, p. 129). It can be deduced from these properties that the Nash bargain $u^{*}$ agreed on by the players must be the (unique) solution to the maximization problem

$$
\max _{u \in U, u \geqq u^{q}}\left(u_{\pi}-u_{\pi}^{q}\right) \cdot\left(u_{\mu}-u_{\mu}^{q}\right) .
$$

The Nash bargain $u^{*}$ maximizes the product of both players' utility gains relative to the status quo. Graphically, one looks at the family of hyperbolas defined by all pairs $\left(u_{\pi}, u_{\mu}\right)$ which result in a given product $k$ of utility gains. The tangency point of the subset of Pareto-efficient and individually rational ${ }^{7}$ elements of $U$ and the highest hyperbola still having a point in common with this set defines $u^{*}$.

The Nash solution has been generalized by Kalai (1977) to reflect asymmetries between players that are not already covered by any asymmetry of $U$. The asymmetric Nash bargain with bargaining powers $\alpha \geq 0$ and $\beta=1-\alpha \geq 0$ for EP and CM, respectively, is the solution $u^{*}$ to the maximization problem

$$
\max _{u \in U, u \geqq u^{q}}\left(u_{\pi}-u_{\pi}^{q}\right)^{\alpha} \cdot\left(u_{\mu}-u_{\mu}^{q}\right)^{\beta} .
$$

An asymmetry in bargaining powers can, for example, arise from differences in players' patience (see Section 4).

Consider the simple case of a unidimensional policy space $X=[0,1]$ and the risk-neutral utility functions

$$
u_{\pi}(x) \equiv u(\pi, x)=-|\pi-x|
$$

and

$$
u_{\mu}(x) \equiv u(\mu, x)=-|\mu-x|
$$

for $\pi, \mu \in X$. Suppose without loss of generality that $\pi<\mu$ and take the status quo to be $q=0$, i. e. let there be gains from trade. Then, $u^{q}=(-\pi,-\mu)$ is players' status quo utility. Agreement on $x=\pi$ results in the utility pair $(0, \pi-\mu)$, agreement on $x=\mu$ results in $(\pi-\mu, 0)$ (see Fig. 3). Mapping any possible agreement $x \in X$ to the corresponding utility levels for both players yields the set $U$ depicted in Fig. $4 .^{8}$ The Nash bargain $u^{*}$ does, as indicated in Fig. 4, correspond to agreement on $x=\pi$, i. e. the ideal point of the player closer to the status quo, EP. Algebraically, restricting attention to Pareto-efficient agreements $x \in[\pi, \mu]$ judged better by both players than the status quo, one maximizes ${ }^{9}$

$$
f\left(u_{\pi}, u_{\mu}\right)=\left(u_{\pi}-(-\pi)\right)\left(u_{\mu}-(-\mu)\right)
$$

\footnotetext{
${ }^{6}$ Technical conditions on $\left\langle U, u^{q}\right\rangle$ like convexity and compactness are usually imposed in order to guarantee existence and uniqueness of the solution.

${ }^{7}$ Individual rationality combined with the voluntary character of any bilateral agreement imply $u^{*} \geqq u^{q}$.

${ }^{8}$ The bargaining set $U^{\prime}=\left\{\left(u_{\pi}, u_{\mu}\right) \in \mathbb{R}_{-}^{2}: u_{\pi}+u_{\mu} \leq \pi-\mu\right\}$ can be obtained from $U$ by adding irrelevant alternatives. It satisfies the technical assumptions typically used by the Nash bargaining solution (it is convex, closed, and bounded from above).

${ }^{9}$ For ease of exposition, we do not distinguish between utility functions $u_{i}$ and particular components of elements of $U$, i. e. a utility level for player $i$, in our notation. Whether $u_{\pi}$ refers to the utility function itself or a particular utility level $u_{\pi}(x)$, corresponding to some policy $x$, should be clear from the context.
} 


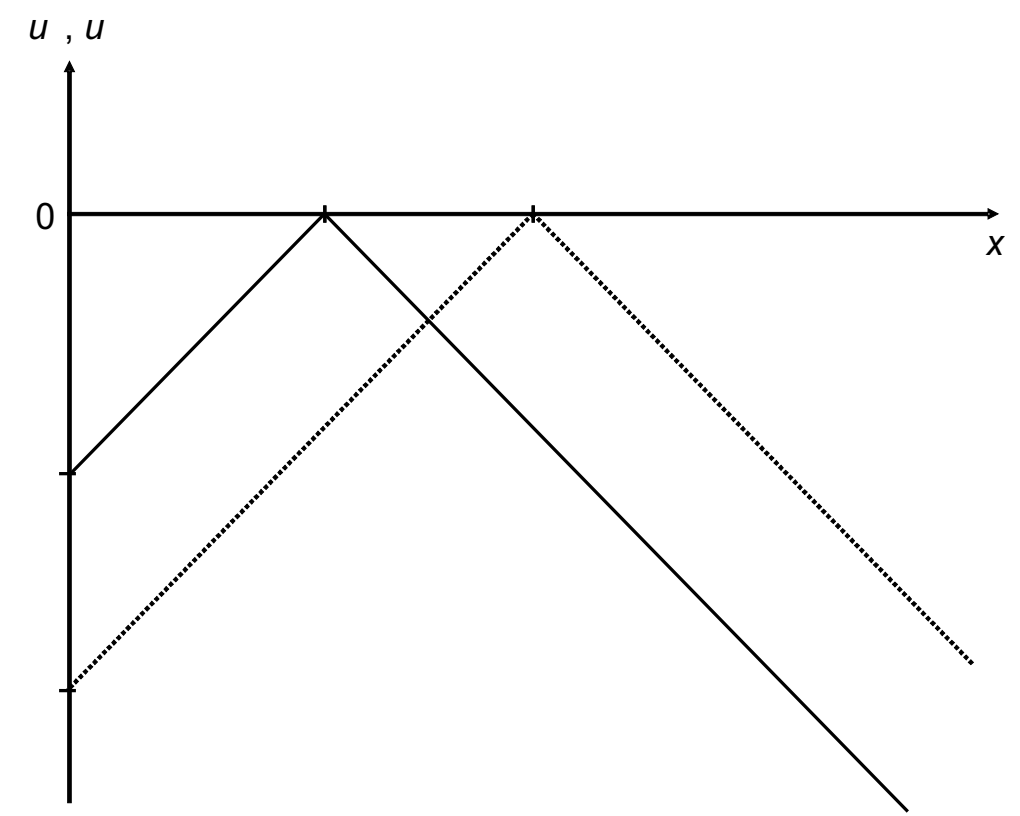

Figure 3: A unidimensional policy space and risk-neutrality

subject to $\left(u_{\pi}, u_{\mu}\right) \geqq u^{q}$ and $u_{\pi}+u_{\mu}=\pi-\mu$. Substituting the latter condition into (5), one obtains

$$
\frac{d f}{d u_{\pi}}=\frac{d\left[\left(u_{\pi}+\pi\right)\left(\pi-\mu-u_{\pi}+\mu\right)\right]}{d u_{\pi}}=-2 u_{\pi},
$$

i. e. the Nash product $f$ increases for $u_{\pi} \leq 0$ and is maximal for $u_{\pi}=0$. This implies $u^{*}=(0, \pi-\mu)$ and agreement on $x^{*}=\pi$. The party less eager to replace the status quo, in our example EP, gets exactly its ideal policy; the other one, here CM, has to be satisfied with at least some improvement of the situation. ${ }^{10}$ Hence, intuitively appealing assertions of EP and CM 'meeting in the middle' between their ideal policies - based on a superficial symmetry between the two players - are too quick.

If EP's and CM's utility is not linear in distance to the respective ideal point but strictly concave (corresponding to risk aversion or decreasing marginal returns from moving closer to the considered player's ideal point, e.g. $\left.\tilde{u}(\lambda, x)=-(\lambda-x)^{2}\right)$, then the Pareto frontier connecting the two extreme utility levels $\bar{u} \equiv(0, \tilde{u}(\mu, \pi))$ and $\underline{u} \equiv(\tilde{u}(\pi, \mu), 0)$ becomes strictly concave as well. Keeping the symmetry between EP and CM (they have the same utility function $u\left(\lambda_{i}, x\right)$, just different ideal points), this implies that the hyperbola corresponding to the highest attainable level of the product of both players' utility gains touches $U$ 's Pareto frontier $P(U)$ no longer at its right endpoint, $\bar{u}$, but somewhere between it and the middle of the curve. ${ }^{11}$

Suppose that EP and CM try to reach an agreement in a more than unidimensional

\footnotetext{
${ }^{10}$ Both players enjoy equal net utility gains in this linear case. If utility is assumed to be interpersonally comparable, this means both benefit (relative to status quo) equally from the agreement.

${ }^{11}$ It cannot be to the left of the Pareto curve's midpoint, which would correspond to an agreement $x$ closer to CM's than to EP's ideal point, because the Pareto frontier remains symmetric to the $45^{\circ}$-line.
} 


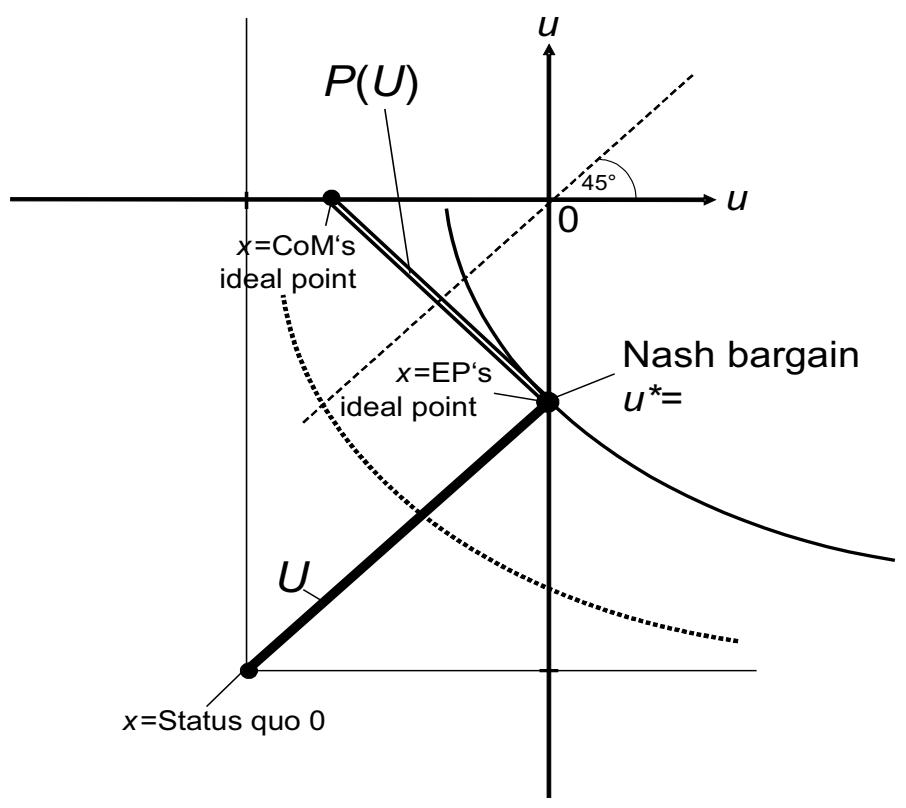

Figure 4: Bargaining set $U$ and Nash bargain $u^{*}$

policy space, e.g. the 2-dimensional space shown in Fig. 2. If utility is linearly decreasing in distance, it will decrease (increase) linearly for EP (CM) as one moves from any point on the contract curve $C$ to another one closer to $\mu$. The opposite applies for a move towards $\pi$. Adding constants to players' utility levels or multiplying them by any positive number does not affect the Nash bargain because it results in equivalent utility representations. ${ }^{12}$ For example, the utility representations can be chosen such that $\bar{u}=(0,-d(\mu, 0))$ and $\underline{u}=(-d(\pi, 0), 0)$, respectively, are players' utility levels in the northwestern and southeastern endpoints of contract curve $C$. Then, EP and CM - according to Nash's bargaining solution - will agree on the policy $x$ associated with utility levels $(0,-d(\mu, 0))$. For the configuration shown in Fig. 2 this does not, in contrast to the unidimensional case investigated above, actually correspond to EP's ideal point because the latter would be worse to CM than the status quo. Outcome $x^{*}$ is the Pareto-efficient policy which is the most beneficial to EP among all policies that give CM at least as much utility as the status quo, i. e. satisfy individual rationality. For $d(\pi, 0)<d(\mu, 0)$, CM benefits only weakly from reaching an agreement - its greater dislike of the status quo deprives it from achieving a strict utility increase over the status quo.

The argument concerning the case of concave utility given for the unidimensional case applies also to higher dimensions: As players become (symmetrically) more risk averse, the agreement will slowly improve for the player with greater dislike of the status quo, but still remain biased to his counterpart's favor. Focussing on cases with a differentiable Pareto

\footnotetext{
${ }^{12}$ Von Neumann-Morgenstern expected utility representation of preferences $u$ is equivalent to any representation $\tilde{u}$ if one results from the other by applying an affine transformation, i. e. $\tilde{u}=\rho+\omega \cdot u$ for $\rho, \omega \in \mathbb{R}$ and $\omega>0$.
} 
frontier, this can be summarized as follows:

Proposition 1 Assume that preferences of EP and CM are represented by utility functions $u_{i}(x) \equiv u\left(d\left(\lambda_{i}, x\right)\right)$ which are strictly decreasing and weakly concave in $d\left(\lambda_{i}, x\right)$ and yield a Pareto frontier described by a function $\phi: u_{\pi}(x) \mapsto \max \left\{u_{\mu}(y): y \in X \wedge u_{\pi}(y)=u_{\pi}(x)\right\}$ which is differentiable on the interior of the contract curve. Then the symmetric Nash bargain $x^{*}(\pi, \mu) \equiv x^{*}$ is closer to the ideal point which is closer to the status quo, i.e.

$$
d(\pi, 0)<d(\mu, 0) \Longleftrightarrow d\left(\pi, x^{*}\right)<d\left(\mu, x^{*}\right),
$$

whenever there are gains from trade.

The proof is provided in the appendix.

In case of convex utility, i. e. if players are risk-loving or experience increasing marginal utility the closer $x$ gets to their ideal point, the Nash bargain in general is no longer well-defined. However, for the special case of spatial preferences considered in this paper, the individually rational and Pareto-efficient policy $x^{*}$ most beneficial to the player with smallest status quo distance remains the unique prediction. ${ }^{13}$

Status quo bias is robust to the introduction of moderately asymmetric bargaining powers $\alpha$ and $\beta=1-\alpha$ in the Nash bargaining solution. For the one-dimensional linear case studied above, the asymmetric Nash solution is the maximizer of

$$
f\left(u_{\pi}, u_{\mu}\right)=\left(u_{\pi}+\pi\right)^{\alpha} \cdot\left(u_{\mu}+\mu\right)^{1-\alpha}
$$

constrained by $\left(u_{\pi}, u_{\mu}\right) \geqq u^{q}$ and $u_{\pi}+u_{\mu}=\pi-\mu$. One can equivalently calculate the maximizer of $\tilde{f}\left(u_{\pi}, u_{\mu}\right)=\ln f\left(u_{\pi}, u_{\mu}\right)$ which, after re-arranging, yields

$$
\frac{d \tilde{f}}{d u_{\pi}}=\frac{u_{\pi}-2 \alpha \pi+\pi}{u_{\pi}^{2}-\pi^{2}}=0
$$

or

$$
u_{\pi}=\pi(2 \alpha-1)
$$

together with $\left(u_{\pi}, u_{\mu}\right)>u^{q}$ as necessary conditions for an interior solution. Assuming $\pi<\mu$, the critical level of EP's bargaining power $\alpha^{c}$ below which the asymmetric Nash bargain would actually turn out closer to CM's than to EP's ideal point, i. e. $x^{*}>(\pi+\mu) / 2$, is

$$
\alpha^{c}=\frac{3 \pi-\mu}{4 \pi} .
$$

This is always smaller than $1 / 2$ (considering the case of $\pi \leq \mu$ ) and may even be negative. Only a sufficiently pronounced asymmetry in bargaining powers can overcome status quo bias.

\footnotetext{
${ }^{13}$ See e.g. Osborne and Rubinstein (1990, pp. 16ff) or Harsanyi (1956) for justifications of the solution $u^{*}$ to (1), which corresponds to $x^{*}$, as the expected bargaining result that do not rely on Nash's original axiomatic argument and do not assume convexity.
} 
(a)

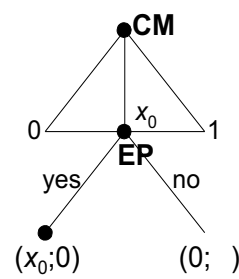

$(x ; t)$ : agreement on $(x, 1-x)$ in period $t$

$(0 ; \infty)$ : disagreement outcome (b)

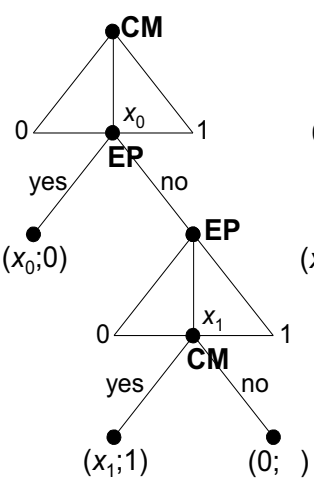

$(0 ; \infty)$ (c)

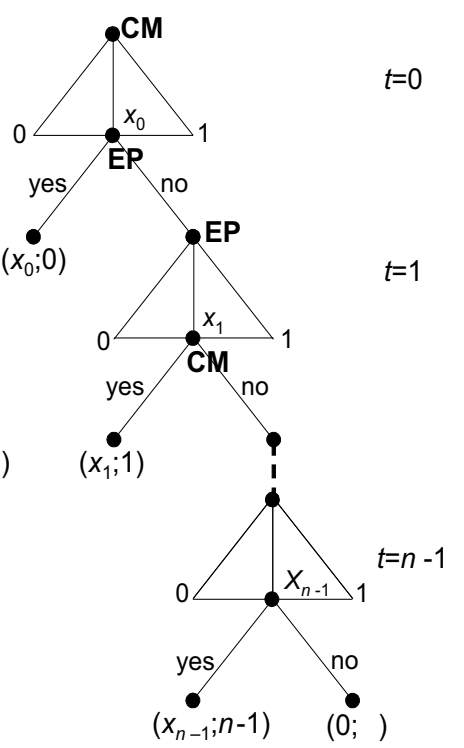

Figure 5: Ultimatum game form, 2-stage and $n$-stage alternating offers bargaining game forms

\section{Alternating Offers Bargaining}

The Nash solution investigated above - like other solution concepts in cooperative game theory $^{14}$ - identify particularly 'reasonable' (as formalized by axioms) binding agreements between two bargainers without specifying an actual process of negotiation. Non-cooperative models of bargaining, in contrast, consider bargaining as a fully specified game; any agreements prior to playing the game are assumed to be non-binding and are hence ignored.

Again, consider the unidimensional policy space $X=[0,1]$, ideal points $\pi$ and $\mu$ for EP and CM where without loss of generality $\pi \leq \mu$, and status quo $q=0$ (see Fig. 3 ). ${ }^{15}$ Then, the set of Pareto-optimal policies which satisfy individual rationality is $\tilde{X}=[\pi, \min \{\mu, 2 \pi\}]$ because any $x>2 \pi$ would be worse to EP than the status quo while any $x<\pi$ or $x>\mu$ could be improved upon to the benefit of both EP and CM. We will write $\mu^{\prime} \equiv \min \{\mu, 2 \pi\}$ in the following and restrict proposals to $\tilde{X}$.

One of the simplest non-cooperative models of bilateral bargaining is the ultimatum game illustrated in Fig. 5(a). It supposes that CM moves first and makes a proposal $x_{0} \in\left[\pi, \mu^{\prime}\right]$ and that EP can only respond to the proposal by either rejecting or accepting it. This corresponds to a take-it-or-leave-it agenda setting game. For simplicity, let both players' utility functions be linear as in (3) and (4). A very clear prediction is obtained for this simple bargaining protocol. Namely, the ultimatum game has a unique subgame perfect equilibrium (SPE). Any strategy of EP which prescribes rejection in case of a

\footnotetext{
${ }^{14}$ See e.g. the axiomatic approach to bargaining between groups proposed by Chae and Heidhues (2002).

${ }^{15} q \in(0, \pi)$ and $q \in(\mu, 1]$ would lead to qualitatively identical conclusions, where in the latter case CM is the player with smaller status quo distance. For $q \in(\pi, \mu)$ there is no mutually beneficial policy change and hence $x^{*} \equiv q$.
} 
proposal $x_{0} \in\left[\pi, \mu^{\prime}\right)$ would constitute an incredible threat; namely, it is suboptimal for EP to reject a utility improvement of $\Delta=-\left(x_{0}-\pi\right)-(-\pi)=2 \pi-x_{0}>0$ relative to the status quo. The SPE concept rules this out. The only candidates for EP's strategy in a SPE are therefore the strategy $s_{2}^{\prime}$ which accepts any offer $x_{0} \in[\pi, 2 \pi]$ but rejects $x_{0}=\mu^{\prime}=2 \pi$ in case of $\mu \geq 2 \pi$, and the strategy $s_{2}^{*}$ which accepts any offer $x_{0} \in\left[\pi, \mu^{\prime}\right]{ }^{16}$ The strategy profile $\left(\mu^{\prime}, s_{2}^{*}\right)$ is a SPE - specifying that CM asks for its maximal feasible gains from trade (either implementing its ideal point or the point closest to it that is no worse to EP than the status quo), and EP accepts. ${ }^{17}$ The profile $\left(\mu^{\prime}, s_{2}^{\prime}\right)$ is no SPE since it is sub-optimal for CM to propose $s_{1}=\mu^{\prime}$ in case of $\mu^{\prime}=2 \pi$ (which is rejected by $s_{2}^{\prime}$ ) anticipating that any proposal $s_{1}<2 \pi$ would be accepted by EP. Since, however, no such proposal $s_{1}$ is optimal $-\max \left[\pi, \mu^{\prime}\right)$ does not exist $-\left(\mu^{\prime}, s_{2}^{*}\right)$ is the unique SPE of the ultimatum game and $x^{*}=\mu^{\prime}$ is its outcome in policy terms.

This SPE prediction reflects overwhelming bargaining power of CM as the proposer in the ultimatum game. Similarly, if EP were the proposer and CM the responder, $x^{*}=\pi$ would be the very asymmetric outcome. ${ }^{18}$ Ultimatum bargaining has been proposed as a model for decision-making in the Conciliation Committee by Steunenberg and Dimitrova (1999). They argue that, although officially the Committee is co-chaired by CM's presiding member and EP's Vice-President, the former exerts agenda setting power due to its more important role at the preparatory stage before the committee meets. Crombez (2000), in contrast, assumes that the EP takes the lead and makes a take-it-or-leave-it proposal to CM. No matter which of these contradicting assertions about who moves first is a better model of reality, ultimatum bargaining rests on more than agenda setting. The SPE prediction is driven by the first mover's opportunity to credibly make a take-it-or-leaveit offer or, equivalently, to irrevocably commit to its initial proposal. In our view, this is unrealistic assumption for the Conciliation Committee. Hence, ultimatum bargaining should be regarded as, at best, a coarse first approximation.

SPE predictions already change significantly if, a little more realistically, the game has two stages as in Fig. 5 (b). Suppose that after having rejected an offer $x_{0}$, EP can make a counter-offer $x_{1}$. The overall surplus division will then reflect EP's advantage of making a credible take-it-or-leave-it offer at stage 2 (referred to as period $t=1$ ), while possible renegotiation in stage 2 renders any proclaimed commitment to a particular division by $\mathrm{CM}$ in stage 1 incredible.

Yet more realistically, one can consider the alternating offers bargaining game with $n$ stages illustrated in figure $5(\mathrm{c})$. Let players' preferences over outcomes $(x, t)$, specifying

\footnotetext{
${ }^{16}$ Considering offers from the entire interval $[0,1]$ instead of only those from $\left[\pi, \mu^{\prime}\right]$ does not affect results. In the former case, $s_{2}^{*}$ would prescribe acceptance of any $x \in[0,2 \pi]$ for EP, but CM prefers not to propose any $x<\pi$ or, in fact, $x<\mu^{\prime}$.

${ }^{17}$ Acceptance by EP is only a weak best response for $\mu^{\prime}=2 \pi$. This Nash equilibrium is therefore not strict.

${ }^{18}$ The issue of responder's individual rationality does not arise if $X$ is unidimensional and the player closer to the status quo proposes.
} 
the agreed policy and the time of agreement, be of the particularly simple type

$$
\begin{aligned}
& U_{\pi}(x, t)=U(\pi, x, t)=\delta_{\pi}^{t} \cdot u(\pi, x) \\
& U_{\mu}(x, t)=U(\mu, x, t)=\delta_{\mu}^{t} \cdot u(\mu, x)
\end{aligned}
$$

for discount factors $\delta_{i} \in(0,1)$, which reflect players' patience, and function

$$
u\left(\lambda_{i}, x\right)=\lambda_{i}-\left|\lambda_{i}-x\right|,
$$

which represents players' spatial preferences in any fixed period $t$. Utility functions $U_{\pi}$ and $U_{\mu}$ formalize indifference between an eventual failure of negotiations (no agreement reached in the final period and thus the status quo prevails) and any earlier confirmation of the status quo (agreement on status quo policy $q=0$ in period $t<n-1$ ) because $U(\lambda, 0, t)=0$ for any $t=0, \ldots, n-1$. The same would be true - and the following results would be unchanged - if $u$ is multiplied by any constant $\omega>0$; thus, players' utility levels in their respective ideal points e. g. could be chosen to both equal 1.

Consider first $n=2$, the two-stage game depicted in Fig. 5(b). With preference specification (6), EP would anticipate to achieve $x_{1}^{*}=\pi$ in period $t=1$ if it rejects CM's proposal $x_{0}$. Knowing that $x_{1}^{*}$ would result in utility level $U_{\pi}(\pi, 1)=\delta_{\pi} \pi$ for $\mathrm{EP}, \mathrm{CM}$ optimally chooses its proposal $x_{0}$ such that EP weakly prefers accepting it to outcome $(x, t)=(\pi, 1)$, i. e.

$$
\begin{aligned}
U_{\pi}\left(x_{0}^{*}, 0\right)=\pi-\left(x_{0}^{*}-\pi\right) & \stackrel{!}{=} \delta_{\pi} \pi=U_{\pi}(\pi, 1) \\
& \Longleftrightarrow \quad x_{0}^{*}=2 \pi-\delta_{\pi} \pi .
\end{aligned}
$$

CM's strategy of proposing $x_{0}^{*}$ in $t=0$ and accepting any $x_{1} \in\left[\pi, \mu^{\prime}\right]$ in $t=1$, and EP's strategy of accepting offers $x_{0} \leq x_{0}^{*}$ in $t=0$ and proposing $x_{1}^{*}$ in $t=1$ form the unique SPE of the game. ${ }^{19}$ Hence in the alternating offers bargaining game with two stages in which CM proposes first, $x_{0}^{*}=2 \pi-\delta_{\pi} \pi$ is proposed and immediately accepted. If EP had the right to propose first, the equilibrium outcome would be $x_{0}^{*}=\delta_{\mu} \mu^{\prime}$ instead.

Above backward induction argument of players' correctly anticipating how much they have to offer in order to make their counterpart at least indifferent between accepting an offer and rejecting it in favor of playing the continuation game can be applied to alternating offers bargaining for any given number $n$ of stages. One obtains

Proposition 2 Given ideal points $\pi \leq \mu$ and the finite set of periods $T=\{0, \ldots, n-1\}$, $n \geq 1$, the unique SPE outcome of the alternating offers bargaining game with $n$ stages and preferences described by (6) and (7) in which CM proposes first is the efficient outcome $\left(x^{*}\left(n, \delta_{\mu}, \delta_{\pi}\right) ; 0\right)$ with

$$
x^{*}\left(n, \delta_{\mu}, \delta_{\pi}\right)=\sum_{t=0}^{\left\lfloor\frac{n-1}{2}\right\rfloor}\left(\delta_{\mu} \delta_{\pi}\right)^{t} \cdot \mu^{\prime}+\sum_{t=0}^{\left\lfloor\frac{n-2}{2}\right\rfloor}\left(\delta_{\mu} \delta_{\pi}\right)^{t} \cdot\left(2 \pi-\delta_{\pi} \pi-\mu^{\prime}\right)-\delta_{\pi} \cdot \sum_{t=0}^{\left\lfloor\frac{n-3}{2}\right\rfloor}\left(\delta_{\mu} \delta_{\pi}\right)^{t} \cdot \pi
$$

where $\lfloor y\rfloor$ denotes the biggest integer smaller than or equal to $y$.

\footnotetext{
${ }^{19}$ Recall that strategies are complete plans of action defining what a player does even in situations that are impossible given the correct implementation of own and others' specified choices.
} 
The proof is given in the appendix. Prop. 2 contains a compact description of the predicted outcome of bargaining in the Conciliation Committee for a given number of (potential) bargaining stages $n$ and players who discount future utility. ${ }^{20}$

A player's opportunity to make the final take-it-or-leave-it offer in period $t=n-1$ is a source of bargaining strength. For small $n$ this may over-compensate status quo bias: As seen above, if $n=1$ and CM proposes, the SPE outcome is $x=\mu^{\prime}$, i. e. either CM obtains its ideal point $\mu$ or $x=2 \pi$ which makes CM the only party to strictly benefit from a status quo change despite greater distance to it. ${ }^{21}$

EU deadlines for reaching a decision in the Conciliation Committee combined with the specific schedules of its members may define some final period in real negotiations. ${ }^{22}$ Yet, it seems arbitrary to use any particular $n$ in the model. A focal benchmark case is therefore bargaining without any fixed final round.

Though absence of a final period forbids the backward induction argument for finite horizon bargaining underlying (8), there is an even neater solution for an infinite time horizon. Rubinstein's (1982) main result - concerning much more general types of preferences than the linear case studied above - implies that

$$
x^{*}\left(\delta_{\mu}, \delta_{\pi}\right)=\frac{2 \pi\left(1-\delta_{\pi}\right)}{1-\delta_{\pi} \delta_{\mu}}
$$

is the unique SPE policy outcome, which is proposed by CM and immediately accepted by EP. Non-trivially, it is indeed the limit of (8) as $n \rightarrow \infty$ :

$$
\begin{aligned}
\lim _{n \rightarrow \infty} x^{*}\left(n, \delta_{\mu}, \delta_{\pi}\right) & =\sum_{t=0}^{\infty}\left(\delta_{\mu} \delta_{\pi}\right)^{t} \cdot \mu^{\prime}+\sum_{t=0}^{\infty}\left(\delta_{\mu} \delta_{\pi}\right)^{t} \cdot\left(2 \pi-\delta_{\pi} \pi-\mu^{\prime}\right)-\delta_{\pi} \cdot \sum_{t=0}^{\infty}\left(\delta_{\mu} \delta_{\pi}\right)^{t} \cdot \pi \\
& =\frac{\mu^{\prime}}{1-\delta_{\mu} \delta_{\pi}}+\frac{2 \pi-\delta_{\pi} \pi-\mu^{\prime}}{1-\delta_{\mu} \delta_{\pi}}-\frac{\delta_{\pi} \cdot \pi}{1-\delta_{\mu} \delta_{\pi}} \\
& =x^{*}\left(\delta_{\mu}, \delta_{\pi}\right)
\end{aligned}
$$

In case that $\mathrm{EP}$ is the first to propose, the $\mathrm{SPE}$ outcome is

$$
x^{*}\left(\delta_{\pi}, \delta_{\mu}\right)=\delta_{\mu} \frac{2 \pi\left(1-\delta_{\pi}\right)}{1-\delta_{\pi} \delta_{\mu}}
$$

instead (still considering $\pi \leq \mu-$ for $\pi>\mu$ the roles of $\mu$ and $\pi$ are to be switched).

Assuming identical patience $\delta_{\mu}=\delta_{\pi}=\delta \in(0,1)$ and considering the limit case of extreme patience, $\delta \rightarrow 1$, both (9) and (10) converge to $\lim _{\delta \rightarrow 1} x^{*}(\delta, \delta)=\pi$. So, no matter

\footnotetext{
${ }^{20}$ Note the somewhat surprising feature of above SPE that the agreement is influenced by the final period and who proposes in it, but is already reached in $t=0$. This is a consequence of the assumed perfect rationality of EP and $\mathrm{CM}$ and the fact that preferences are considered to be common knowledge.

${ }^{21}$ If $\pi \ll \mu$, i. e if EP is rather satisfied with the status quo while CM is not, the SPE outcome $\mu^{\prime}$ is still very close to EP's ideal point, $\pi$, and far from CM's, $\mu$.

${ }^{22}$ The time for the Conciliation Committee is limited to eight weeks - two weeks devoted to preparation plus six weeks for bargaining. The total period can be extended up to three months. Note that the member state which is holding presidency can postpone the preparatory stage and hence conciliation.
} 
whether CM or EP has the initiative in the Conciliation Committee, the bargaining result amounts to implementation of the ideal point of the player with smaller distance to the status quo. We observe exactly the same pronounced status quo bias as in the linear utility version of Nash bargaining.

This is not surprising: Rubinstein's noncooperative analysis of an explicit, extensiveform bargaining game and Nash's cooperative analysis of the implications of "reasonable properties" are very closely related. This was first pointed out by Binmore (1987). Namely, if the time that passes between each rejection and counter-offer becomes negligibly small, while the discount factors $\delta_{\mu}$ and $\delta_{\pi}$ applied to payoffs delayed by a fixed time interval stay constant (so that players become almost indifferent to the period of agreement) the SPE payoffs to CM and EP approach the utility levels of the asymmetric Nash bargaining solution with bargaining powers

$$
\beta=\frac{\ln \delta_{2}}{\ln \delta_{1}+\ln \delta_{2}} \quad \text { and } \quad \alpha=1-\beta
$$

for CM and EP of the bargaining problem defined by players' respective, possibly non-linear utility of policy $x$ for all $x \in X=[0,1]$ and status quo $q=0$ (cf. Section 3). Rubinstein's model of alternating offers bargaining thereby provides a foundation of the asymmetry in (2) based on perfectly rational strategic interaction with asymmetric patience.

The close relation between the Nash solution and Rubinstein bargaining with discounting implies that the former's status quo bias established in Prop. 1 is also a feature of the latter, at least if EP and CM do neither discount future utility too much (so that $x^{*}\left(\delta_{\mu}, \delta_{\pi}\right)$ is close to its Nash solution limit) nor too asymmetrically (so that $\alpha$ is still above the critical level $\alpha^{c}$ identified in Sect. 3). This applies to fairly general stage-level utility functions $u\left(\lambda_{i}, x\right)$ and multidimensional policy spaces as long as one crucial aspect of the preferences defined by (7) is kept: For any policy $x$ that improves upon the status quo from EP's and CM's perspective, both EP and CM prefer to agree on it rather sooner than later. Hence, if the stage utility function

$$
u(\lambda, x)=-|\lambda-x|,
$$

which was a straightforward choice in Sect. 3 and for the ultimatum game, were used in intertemporal utility functions (6) instead of $u(\lambda, x)=\lambda-|\lambda-x|$, one would obtain neither above SPE outcome $x^{*}\left(\delta_{\mu}, \delta_{\pi}\right)$ nor status quo bias. $U(\lambda, x, t)=\delta^{t} \cdot u(\lambda, x)$ in this case would specify indifference of both players concerning the time of an agreement on their respective ideal point $(U(\lambda, \lambda, t)=0$ for any $t \geq 0)$. And yet more oddly, an agreement on anything other than one's ideal point would be judged better by $U$, the more distant in time it is $\left(\delta^{t} u(\lambda, x)<0\right.$ increases in $t$ for $\left.x \neq \lambda\right) \cdot{ }^{23}$ This stresses the point made in Sect. 2 concerning the importance of appropriately representing spatial preferences in a bargaining context.

Of course, stationary discounting is just one way to model EP's and CM's impatience in implementing a Pareto-improvement of the status quo. ${ }^{24}$ An appealing alternative choice

\footnotetext{
${ }^{23} U$ captures the 'suffering' from a non-ideal policy and that a utility loss tomorrow is preferred to one today. The negative consequences of the status quo are not accounted for.

${ }^{24}$ The case of non-stationary discounting is considered by Rusinowska (2002).
} 
is

$$
\begin{aligned}
& U_{\pi}(x, t)=U(\pi, x, t)=u(\pi, x)-t \cdot c_{\pi} \\
& U_{\mu}(x, t)=U(\mu, x, t)=u(\mu, x)-t \cdot c_{\mu},
\end{aligned}
$$

which formalizes that EP and CM suffer a fixed utility cost of $c_{\pi} \geq 0$ and $c_{\mu} \geq 0$, respectively, for any period of unsuccessful bargaining and delay. Immediate agreement on some proposal $x_{0}=x^{*}$ which gives the responding player at least as much utility as rejection and a counter-proposal $x_{1}$ which would in equilibrium be accepted by the original proposer (i. e. gives at least as much utility as rejection and a counter-proposal $x_{2}$ which would ..., etc.) is again an SPE outcome. ${ }^{25}$ The precise agreement, again assuming that CM proposes first, is found by solving the equations

$$
\begin{aligned}
& x_{0}=v_{\pi}\left(x_{1}\right) \\
& x_{1}=v_{\mu}\left(x_{0}\right),
\end{aligned}
$$

where $v_{i}(\tilde{x})$ denotes the from player $j$ 's point of view best policy $x$ whose implementation in $t=0$ (or, in general, period $t$ ) is weakly preferred by player $i$ to implementation of $\tilde{x}$ in $t=1$ (or, in general, period $t+1$ ). In a loose sense, $v_{i}(\tilde{x})$ is the present value to player $i$ of a refusal, and player $j$ can obtain $i$ 's consent only by offering at least something as good as $v_{i}(\tilde{x})$. Function $v_{i}(\tilde{x})$ takes into account player $i$ 's individual rationality (e.g. EP will never agree to any $x>2 \pi)$, and it may actually give more utility to player $i$ than $(x, t)=(\tilde{x}, 1)$ would if that is in player $j$ 's own interest. Functions $v_{\pi}\left(x_{1}\right)$ and $v_{\mu}\left(x_{0}\right)$ are illustrated in Fig. 6 for the case of $c_{\pi}>c_{\mu}$ and $\mu>2 \pi{ }^{26}$ The figure covers all policies $x$ in $[0,1]$ rather than only the Pareto-efficient and individually rational ones in $\left[\pi, \mu^{\prime}\right]$, confirming that the latter restriction is without consequences. The unique intersection point corresponds to the following solution to (12):

$$
\begin{aligned}
& x_{0}^{*}\left(c_{\mu}, c_{\pi}\right)=\mu^{\prime}=2 \pi \\
& x_{1}^{*}\left(c_{\mu}, c_{\pi}\right)=\mu^{\prime}-c_{\mu} .
\end{aligned}
$$

Policy $x_{0}^{*}\left(c_{\mu}, c_{\pi}\right)$ is the unique SPE outcome in case that CM proposes first, and $x_{1}^{*}\left(c_{\mu}, c_{\pi}\right)$ would be the unique SPE outcome of the same game if EP were to propose first. ${ }^{27}$ For $c_{\pi}<c_{\mu}$, the corresponding values are ${ }^{28}$

$$
\begin{aligned}
& x_{0}^{*}\left(c_{\mu}, c_{\pi}\right)=\pi+c_{\pi} \\
& x_{1}^{*}\left(c_{\mu}, c_{\pi}\right)=\pi .
\end{aligned}
$$

Hence the infinite horizon alternating offers bargaining game in which players experience a constant cost for any period of delay, rather than discount utility, predicts that the player

\footnotetext{
${ }^{25} \mathrm{It}$ is unique for $c_{\pi} \neq c_{\mu}$.

${ }^{26} \mathrm{~A}$ similar picture could be used to graphically derive the SPE policy $x^{*}\left(\delta_{\mu}, \delta_{\pi}\right)$ for above discounting time preferences. $v_{\pi}\left(x_{1}\right)$ and $v_{\mu}\left(x_{0}\right)$ would have similar shapes but different kinks and slopes. For example, $x_{0}=v_{\pi}\left(x_{1}\right)$ would be defined by the points $(2 \pi, 1),(2 \pi, 2 \pi),\left(2 \pi-\delta_{\pi} \pi, \pi\right)$, and $(2 \pi, 0)$ in $x_{0}-x_{1}$ coordinates.

${ }^{27}$ For $\mu^{\prime}-c_{\mu}<\pi$, the outcome would be $x_{1}^{*}\left(c_{\mu}, c_{\pi}\right)=\pi$, i. e. EP as the initial proposer can - in view of both players' high costs of any delay - implement its ideal point despite greater bargaining costs.

${ }^{28}$ Analogous to above footnoote, $x_{0}^{*}\left(c_{\mu}, c_{\pi}\right)=\mu^{\prime}$ for $c_{\pi}>\mu^{\prime}$.
} 


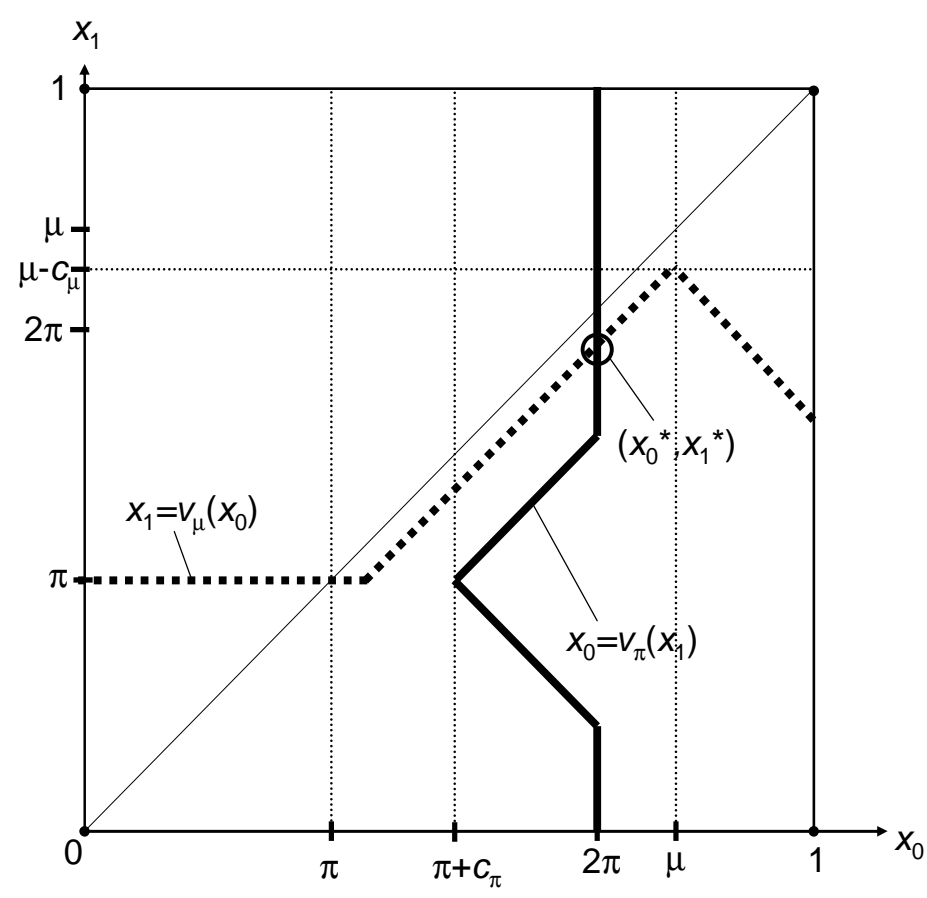

Figure 6: Rubinstein bargaining with constant costs of delay $c_{\pi}$ and $c_{\mu}$

with lower costs of delay gets exactly or approximately his ideal point if costs of delay are small. The intuition for this result is that both EP and CM correctly anticipate that the player with smaller cost would win any 'war of attrition' started by a refusal of the initial proposal.

Rubinstein bargaining with constant costs of delay is less commonly used in applications compared to the discounting version not only because of this rather extreme ${ }^{29}$ prediction and the lack of a close relationship with other bargaining models such as the Nash solution. In addition, there is no unique SPE prediction for the focal case of both EP and CM having identical costs of delay. ${ }^{30}$ Assuming that either EP or CM has smaller costs of delay, the two will only by coincidence (e.g. for $\mu=3 \pi$ ) agree on a policy in the middle of their respective ideal points. Also, there is slight status quo bias because the individual rationality constraint of the player closer to $q$ may bind, while that of his counterpart cannot bind at least in the linear case. However, this is only an issue for particular $\pi-\mu$ combinations and if the player with greater status quo distance proposes first.

\footnotetext{
${ }^{29}$ Note that the strong bias of above SPE towards the player with smaller costs of delay does not require a big difference between $c_{\mu}$ and $c_{\pi}$, but holds for even the tiniest gap between them. This is one of the reasons for using the term 'extreme'.

${ }^{30}$ For $c_{\pi}=c_{\mu}$, as can be easily checked with Fig. 6, there are infinitely many solutions to (12) and corresponding SPE. Some SPE involve inefficient delay.
} 


\section{Bargaining between Boundedly Rational Agents}

The basic alternating offers model studied in Sect. 4 lends itself to a great multitude of variations. ${ }^{31}$ These e.g. account for different inside or outside options of the two players, can incorporate chance moves that may unexpectedly terminate uncompleted negotiations, or allow for the possibility that CM does not know EP's valuation of policies and vice versa. These models help to evaluate the strategic advantage or disadvantage caused by certain characteristics of players (e. g. status quo distance, time or risk preference) and the assumed bargaining procedure (e.g. a given time horizon, or sequence of offers). All are based on the central assumption that players are perfectly rational. It can be questioned - and numerous laboratory experiments on strategic interaction between individuals emphasize the relevance of this question - whether real human beings are actually capable of reasoning their way through the (potentially infinite) back and forth of offers and counter-offers which underlay above analysis. Moreover, would they actually try to get the 'best deal' close to their ideal point or possibly just want to meet a certain aspiration level or agree on a 'fair deal'?

There is ample experimental evidence that individuals are not only, and in many cases not even primarily, interested in maximizing personal material gains. People satisfice, have an aversion to inequity, and reciprocate friendly or unfriendly behavior - even under conditions of anonymity and despite substantial temptations to free-ride or costs of punishing uncooperative behavior (see e.g. Roth, 1995, Fehr and Gächter, 2002, and Fehr and Schmidt, 2001). This suggests that simple Euclidean preferences are a much greater abstraction than it appears. However, there is at least some evidence (see e.g. Bornstein and Yaniv, 1998, and Kocher and Sutter, 2002) that other-regarding motives play a smaller role in strategic interaction between groups of agents, who like the members of CM and EP have to make intra-group decisions before they interact, than individuals.

Obvious bounds of human intelligence and rationality seem also less restrictive in our context. Professional decision-makers in CM and EP establish common positions and then seek mutually beneficial compromises in often lengthy discussions of every pro and con, aided by expert consultants. This is remote from a typical laboratory experiment in which subjects face a stylized bargaining problem to be solved in minutes or an hour, with monetary rewards in the order of $10-30$ euro. ${ }^{32}$ Moreover, the conventional rationality assumptions are sufficient for the conclusions reached above, but by no means necessary. Simple-minded economic or political agents, who, for example, are 'programmed' to a particular strategy and replaced by others if they are too unsuccessful or who select strategies by imitating successful peers, can end up with highly rational outcomes. They are in fact likely to do so given enough time and a sufficiently stable environment (cf. results on evolutionary game theory and learning collected e. g. by Weibull, 1995, and Fudenberg and

\footnotetext{
${ }^{31}$ Many are collected in Muthoo (1999) and also Osborne and Rubinstein (1990).

${ }^{32}$ This does not question the robustness of puzzling experimental findings themselves, such as rejections of positive offers in ultimatum games. Many experiments yield surprisingly similar results when carried out in different cultures, with different time frames, different levels of abstraction, and material rewards ranging from nothing to more than a monthly income.
} 
Levine, 1998).

A number of bargaining models which suppose boundedly rational agents have been investigated (see Napel, 2002, for an overview). They focus on feedback dynamics and often the co-evolution of entire populations of agents. Agents are assumed to use rules of thumb which are, at best, locally optimizing and involve only a heuristic exploitation of available information. Young's (1993) prominent model of adaptive play considers two populations of agents, representatives of whom are randomly selected in each period to play a simple bargaining game. ${ }^{33}$ Selected agents most of the time choose an optimal reply to a sample of their counterparts' $m$ most recent strategy choices. The size of the sample may differ between both populations. Thus, players form differently informed expectations about their counterpart's strategy in the present period; they act myopically in that they ignore any consequences of their behavior on the other population's beliefs and future choices. Occasionally (formalized by a probability $\varepsilon>0$ ), a selected agent chooses completely at random from his entire set of available strategies.

A stochastic process is defined by these repeated draws of agents and their myopic interaction. The distribution over its states, defined by both populations' $m$ most recent strategy choices, converges to a stationary distribution that is independent of the initial state. If agents sample no more than half of the last $m$ available observations, all samples have positive probability, and any strategy that constitutes a best reply to a given sample has positive probability of being chosen as the respective agent's myopic response to his sample, this stationary distribution turns out to concentrate all weight on states which correspond to the repeated implementation of the asymmetric Nash bargaining solution as $\varepsilon \rightarrow 0$. Agents' bargaining power is proportional to their population's respective sample size.

The relevance of Young's results to modelling bargaining in the Conciliation Committee lies in its further corroboration of the Nash bargaining solution: The agreement which maximizes the product of two bargainers' utility gains over the status quo is again singled out - by a model remote from both Rubinstein's perfectly rational bargainers who exactly know each other's preferences and Nash's axioms. Young makes minimal assumptions on the players' information and rationality, and yet arrives at, roughly speaking, the same conclusions as Nash and Rubinstein. Several other models that make similarly minimal rationality assumptions and confirm the predictions of high-rationality models have been studied (cf. e.g. Binmore, Piccione, and Samuelson, 1998, or van Bragt, Gerding, and La Poutré, 2000). ${ }^{34}$ Their point is that one can have at least some confidence that the Nash-Rubinstein bargaining theory outlined in Sect. 3 and 4 captures essential features of bargaining in a number of contexts.

\footnotetext{
${ }^{33}$ It is a version of the demand game: Both agents simultaneously demand shares of a surplus. If agents' demands in sum amount to no more than the total surplus, both players receive their demands. If demands are incompatible, both players receive nothing.

${ }^{34}$ Of course, there are also a number of models of boundedly rational bargaining which do not confirm SPE-predictions, especially for ultimatum games where experimental evidence has also not been very supportive of them (see e. g. Roth and Erev, 1995, Slonim and Roth, 1998, and Napel, 2003).
} 


\section{Implications for Inter-institutional Power}

One of the main reasons for caring about a reasonable model of decision-making in the Conciliation Committee are the strategic repercussions that even the mere possibility of invoking the Conciliation Committee has on the codecision procedure as a whole. Taking these into account should yield better predictions of policy outcomes. ${ }^{35}$ Moreover, it allows for a more accurate a priori evaluation of whether EP and CM are truly symmetric codecision-makers and of how successful different players, referring to concerned institutions as well as their individual members, will be on average given the decision procedure and compared e.g. to possible amendments.

Average success, assessed by making reality-informed or normatively motivated distributional assumptions about preferences and using above equilibrium predictions, is one useful indicator of potential biases in codecision. It does in general, considering more than two players, not reveal who is decisive or influential for realized policy outcomes, i. e. which players are how powerful in defining the results of EU codecision. This is because success can be due to the power to shape a collective decision according to one's individual preferences as well as the luck of finding oneself in agreement with a collective decision on which one had marginal or no influence. Disentangling both is a main purpose of the theory of power measurement.

A priori power in EU decision making has been analyzed by power indices defined on the domain of cooperative simple games in many studies (see e.g. Nurmi, 1998, ch. 7, or Holler and Owen, 2001, for overviews). Simple games condense decision making into a 0-1framework, describing which coalitions can jointly produce a collective decision and which cannot; there is no distinction between different kinds of decisions. Simple games do not account for any procedural details such as the distinction between a vote on a randomly drawn proposal (if such a thing exists), a vote on the proposal of a given agenda-setter, and the pursuit of a bilateral or multilateral agreement within a given bargaining protocol. Modelling bargaining in the Conciliation Committee in that framework and assuming, as above, that CM and EP act like unitary actors (whose respective yes-or-no decision is possibly determined in a different simple game reflecting the decision rule within CM and EP, respectively), one obtains a unanimity game in which both players have equal a priori power. This seems a reasonable assessment at first sight, corresponding to the qualitative conclusions of Crombez (2000) and Garrett and Tsebelis (2000). Quantitative power analysis based on the explicit game-theoretic models studied above can, however, lead to a very different assessment, which to us is more convincing.

To move from Nash or Rubinstein predictions to a quantitative evaluation of the distribution of a priori power in the Conciliation Committee, we apply the framework proposed for power analysis by Napel and Widgrén (2002). It defines a player's a priori power in a given decision procedure and for a given probabilistic distribution of all relevant players' preferences as the expected change to the equilibrium collective decision which would be

\footnotetext{
${ }^{35}$ This assumes knowledge about the preferences of the relevant players. See Napel and Widgrén (2003) for a detailed analysis of the codecision procedure as a whole.
} 
brought about by a change in this player's preferences. ${ }^{36}$ In a spatial voting context, this links power to the question: Which impact would a marginal or fixed-size shift of a given player's ideal policy point have on the collective decision? Note that a player can be powerful in defining the collective decision without being the one to benefit the most from it. This approach to power measurement via a sensitivity analysis of collective decisions generalizes the weighted counting of players' pivot positions which is the basis of conventional power indices. ${ }^{37}$

Assuming a unidimensional policy space $X=[0,1]$ and linear spatial preferences, power analysis of the Conciliation Committee amounts to an investigation of the change in the equilibrium policy outcome effected by a shift of $\pi$ or $\mu$ to the left or right. We consider the effect of marginal shifts of ideal points and hence look at the partial derivatives of the predicted outcome. The Nash bargaining solution yields

$$
x^{*}(\pi, \mu, q)= \begin{cases}\pi & \text { if } q<\pi \leq \mu \text { or } \mu<\pi<q, \\ \mu & \text { if } q<\mu<\pi \text { or } \pi \leq \mu<q, \\ q & \text { otherwise. }\end{cases}
$$

Hence the a posteriori power of EP for a given realization of status quo $q$ and ideal points $\pi$ and $\mu$ is

$$
\frac{\partial x^{*}(\pi, \mu, q)}{\partial \pi}= \begin{cases}1 & \text { if } q<\pi<\mu \text { or } \mu<\pi<q \\ 0 & \text { otherwise. }\end{cases}
$$

This formalizes that any (small) change of the player's ideal point with smaller status quo distance translates into a same-size shift of the agreed policy, provided there is agreement about changing the status quo in at all.

A priori, the expected impact that any marginal shift of EP's ideal policy $\pi$ would have on the collective decision reached in the Conciliation Committee is therefore

$$
\xi_{\pi}=\operatorname{Pr}(\tilde{q}<\tilde{\pi}<\tilde{\mu})+\operatorname{Pr}(\tilde{\mu}<\tilde{\pi}<\tilde{q}),
$$

where $\tilde{q}, \tilde{\pi}$, and $\tilde{\mu}$ denote the random variables corresponding to status quo and ideal points. Not surprisingly, a priori power crucially depends on the distributional assumptions one makes about EP's and CM's ideal points and the status quo. In the absence of any other information, it is at least reasonable to assume that the status quo is uniformly distributed on $X$, implying

$$
\xi_{\pi}=\int_{0}^{1} \operatorname{Pr}(q<\tilde{\pi}<\tilde{\mu}) d q+\int_{0}^{1} \operatorname{Pr}(\tilde{\mu}<\tilde{\pi}<q) d q
$$

If $\tilde{\pi}$ and $\tilde{\lambda}$ are uniformly distributed, too, this evaluates to $\xi_{\pi}=1 / 3$. This number can also be directly deduced from the fact that there are six equally likely orderings of the three

\footnotetext{
${ }^{36}$ Alternatively, and more directly, one may work with probabilistic assumptions about players' actions rather than preferences which then induce actions.

${ }^{37}$ All established indices for simple games, such as the Banzhaf index or the Shapley-Shubik index, can be obtained in this generalized framework by rather simple distribution assumptions and decision protocols. See Napel and Widgrén (2002) for details.
} 
random variables $\tilde{q}, \tilde{\pi}$, and $\tilde{\mu}$, and that in two of them EP has power 1 . In expectation, a change of EP's position on a given policy issue by one marginal unit results in a shift of the collective decision by one third marginal unit. Analogously, one obtains $\xi_{\mu}=1 / 3$. So for uniformly distributed ideal points of EP and CM, the equal-power indication based on a simple game model is confirmed. However, uniformity is no very convincing assumption at the level of EP and CM because it neglects the differences in the internal decision making of both institutions which are an important part of the codecision procedure and its final bargaining stage investigated here. They comprise very different numbers of members and apply different majority rules to reach a decision or find a common position.

To capture this, assume that individual members of EP and CM have random ideal points $\tilde{\pi}_{1}, \ldots, \tilde{\pi}_{k}$ and $\tilde{\mu}_{1}, \ldots, \tilde{\mu}_{m}$ drawn independently from institution-specific symmetric distributions $F$ and $G$ with $k=626$ and $m=15$. For simplicity, we ignore that the 15 members of $\mathrm{CM}$ have different voting weight, i. e. assume simple voting in both EP and CM. ${ }^{38}$ Any change to the status quo then needs at least $p=314$ supporters in EP and $r=11$ supporters in CM, where the latter number approximates the $71 \%$ threshold that exists for weighted voting in the real CM. For a policy $x>q$ to the right of the status quo, the 314-th ideal point counted from the right is the critical position in EP. If the corresponding player prefers $x$ to $q$, so will all 313 voters to his or her right and the proposal is passed. If that player prefers $q$, so will all 312 voters to his or her left and the proposal fails to get the required majority. Similarly, for a policy $x<q$ the 314-th ideal point counted from the left is crucial in EP. We therefore identify $\tilde{\pi}$ with the $p$-th smallest value of $\tilde{\pi}_{1}, \ldots, \tilde{\pi}_{k}$, also called $p$-th order statistic $\tilde{\pi}_{(p)}$, when evaluating policies $x<q$, and with the $(k-p+1)$-th smallest value, i. e. order statistic $\tilde{\pi}_{(k-p+1)}$, when evaluating policies $x>q$. Similarly, CM's random position $\tilde{\mu}$ is given by $\tilde{\mu}_{(r)}$ and $\tilde{\mu}_{(m-r+1)}$ for $x<q$ and $x>q$, respectively.

Assuming that density functions $f$. exist for all these order statistics and denoting cumulative distribution functions by $F$., one obtains:

$$
\begin{aligned}
\xi_{\pi}= & \int_{0}^{1} \operatorname{Pr}\left(q<\tilde{\pi}_{(k-p+1)}<\tilde{\mu}_{(m-r+1)}\right) d q+\int_{0}^{1} \operatorname{Pr}\left(\tilde{\mu}_{(r)}<\tilde{\pi}_{(p)}<q\right) d q \\
= & \int_{0}^{1} \int_{q}^{1} \operatorname{Pr}\left(q<\tilde{\pi}_{(k-p+1)}<\mu\right) f_{\tilde{\mu}_{(m-r+1)}}(\mu) d \mu d q+\int_{0}^{1} \int_{0}^{q} \operatorname{Pr}\left(\mu<\tilde{\pi}_{(p)}<q\right) f_{\tilde{\mu}_{(r)}}(\mu) d \mu d q \\
= & \int_{0}^{1} \int_{q}^{1}\left[F_{\tilde{\pi}_{(k-p+1)}}(\mu)-F_{\tilde{\pi}_{(k-p+1)}}(q)\right] f_{\tilde{\mu}_{(m-r+1)}}(\mu) d \mu d q \\
& +\int_{0}^{1} \int_{0}^{q}\left[F_{\tilde{\pi}_{(p)}}(q)-F_{\tilde{\pi}_{(p)}}(\mu)\right] f_{\tilde{\mu}_{(r)}}(\mu) d \mu d q .
\end{aligned}
$$

One can exploit that for identical symmetric distributions of $\tilde{\pi}_{1}, \ldots, \tilde{\pi}_{k}$, the distributions of order statistics $\tilde{\pi}_{(p)}$ and $\tilde{\pi}_{(k-p+1)}$ satisfy the following symmetry condition (see e. g.

\footnotetext{
${ }^{38}$ This assumption has only small effect on inter-institutional power. Heterogenous weights make the distribution of the pivotal ideal point more similar to the distribution of (large) individual players' ideal points. See the comments at the end of this section.
} 
Arnold et al., 1992, p. 26):

$$
f_{\tilde{\pi}_{(p)}}(x)=f_{\tilde{\pi}_{(k-p+1)}}(1-x) \text { and } F_{\tilde{\pi}_{(p)}}(x)=1-F_{\tilde{\pi}_{(k-p+1)}}(1-x) .
$$

The same applies to $\tilde{\mu}_{(r)}$ and $\tilde{\pi}_{(m-r+1)}$. With (14), one has

$$
\begin{aligned}
& \int_{0}^{1} \int_{q}^{1}\left[F_{\tilde{\pi}_{(k-p+1)}}(\mu)-F_{\tilde{\pi}_{(k-p+1)}}(q)\right] f_{\tilde{\mu}_{(m-r+1)}}(\mu) d \mu d q \\
= & \int_{0}^{1} \int_{q}^{1}\left[F_{\tilde{\pi}_{(p)}}(1-q)-F_{\tilde{\pi}_{(p)}}(1-\mu)\right] f_{\tilde{\mu}_{(r)}}(1-\mu) d \mu d q \\
= & \int_{1}^{0} \int_{\bar{q}}^{0}\left[F_{\tilde{\pi}_{(p)}}(\bar{q})-F_{\tilde{\pi}_{(p)}}(\bar{\mu})\right] f_{\tilde{\mu}_{(r)}}(\bar{\mu}) d \bar{\mu} d \bar{q} \\
= & \int_{0}^{1} \int_{0}^{\bar{q}}\left[F_{\tilde{\pi}_{(p)}}(\bar{q})-F_{\tilde{\pi}_{(p)}}(\bar{\mu})\right] f_{\tilde{\mu}_{(r)}}(\bar{\mu}) d \bar{\mu} d \bar{q}
\end{aligned}
$$

where the second equality results from substitution $(\bar{\mu}, \bar{q}) \equiv(1-\mu, 1-q)$. Hence, given symmetric distributions of ideal points, situations in which both EP and CM want to change policy to the right or, respectively, the left of the status quo are symmetric, and thus

$$
\xi_{\pi}=2 \cdot \int_{0}^{1} \int_{q}^{1}\left[F_{\tilde{\pi}_{(k-p+1)}}(\mu)-F_{\tilde{\pi}_{(k-p+1)}}(q)\right] f_{\tilde{\mu}_{(m-r+1)}}(\mu) d \mu d q .
$$

Now, it is to us a much more reasonable a priori assumption that individual decision makers' ideal points in both EP and CM come from a uniform distribution. Using analogue reasoning for CM, we obtain ${ }^{39}$

$$
\begin{aligned}
& \xi_{\pi}=0.061 \\
& \xi_{\mu}=0.557
\end{aligned}
$$

These numbers do not only diverge significantly from the value of $1 / 3$ derived above, but also indicate a much greater sensitivity of Conciliation Committee decisions to CM than to EP. The reason is the following: First, EP's simple majority rule together with its great number of members implies that the random ideal point of its pivotal member, and hence by our assumption EP's ideal point $\tilde{\pi}$ in the Conciliation Committee, has a distribution (conditioned on the status quo) which is highly concentrated around the mid-point of policy space $X{ }^{40}$ Second, CM's qualified majority rule ensures that the distribution (conditioned on the status quo) of the ideal point of its pivotal member - the 11-th most enthusiastic or 5-th least enthusiastic about changing the status quo in the considered direction - is more spread out and, importantly, skewed with a peak rather close to the status quo. ${ }^{41}$ In other

\footnotetext{
${ }^{39}$ This uses a normal approximation of the $(313,314)$-Beta-distribution of EP's median's ideal point given $\tilde{q}<\tilde{\pi}$.

${ }^{40}$ Considering the case in which EP and CM prefer moving to the right of the status quo, $E\left(\tilde{\pi}_{(k-p+1)}\right)=$ $313 / 627$ with a standard deviation of less than 0.02 .

${ }^{41}$ Similarly, $E\left(\tilde{\mu}_{(m-r+1)}\right)=5 / 16$ with a standard deviation of more than 0.11 .
} 
words, qualified majority implies a rather conservative position of CM in the Conciliation Committee while EP is usually more progressive and centrally located. Status quo bias in bargaining, established in Sect. 3 and 4, translates this into an inter-institutional bargaining advantage for CM, which implies significantly greater average influence and power for CM in the Conciliation Committee.

Party memberships in EP should result in a positive correlation between many ideal points $\tilde{\pi}_{1}, \ldots, \tilde{\pi}_{k}$, which will mitigate the centrality of $\tilde{\pi}$. Also, weighted voting in CM somewhat reduces the skewness. In view of these two issues, $\xi_{\pi}$ and $\xi_{\mu}$ in (15) slightly exaggerates the difference between EP's and CM's average influence in the Conciliation Committee. Nevertheless, the difference is real and highly relevant. It is not identified by any assessment based on simple game indices. It is revealed, though, by inter-institutional power analysis based on explicit game-theoretic models such as those studied in Section 3 or 4 .

\section{Concluding Remarks}

Most observers of European integration agree that EU decision making has developed in the direction of a balanced bicameral system. The set of policy areas to which the codecision procedure applies has been extended, making it the most important decision making procedure of the EU. The procedure itself has been made more symmetric. This paper has studied the final stage of codecision, the Conciliation Committee. It is the key forum in which European Parliament and Council of Ministers - aided by the supposedly neutral Commission - are seeking legislative agreement.

The mostly qualitative assessments of who shapes the compromises reached by EP and $\mathrm{CM}$ - and hence the distribution of power between these two players - by different authors diverge. Some scholars have argued that the European Parliament and the Council of Ministers act as equally influential co-legislators already, while others deduce asymmetry. The divergent assessments are mostly due to differences in modelling, in particular of agenda-setting. Steunenberg and Dimitrova (1999) and Crombez (2000) assume that one player acts as the agenda setter and thus supposedly has the capacity to irrevocably commit to a take-it-or-leave-it policy proposal. The latter presumption is very questionable. Also, there is no agreement between them whether EP or CM has the initiative. Fortunately, this does not matter much if EP and CM can engage in multiple rounds of bargaining and are not too impatient.

To us, the Amsterdam version of codecision gives neither EP nor CM a significant direct procedural advantage. In this respect we side with Tsebelis and Garrett's (2000) assessment. However, in this paper we have argued that the apparent symmetry between Parliament and Council as co-legislating institutions does not imply they are equal partners or equally powerful. This is a non-trivial consequence of the fact that these institutions use distinct internal decision mechanisms - in particular different majority thresholds which provide an indirect procedural (dis-)advantage. Section 6 has discussed this issue in detail, based on our earlier deduction of status quo bias in Conciliation Committee de- 
cisions from standard bargaining models. While both institutions are formally symmetric in the Conciliation Committee, different majority thresholds imply different (average) bargaining positions. This creates a significant asymmetry in the Conciliation Committee with greater influence for the on average more conservative Council of Ministers (referring to smaller interest in amending the status quo). The gradual shift towards bicameralism observed in the past is therefore 'incomplete' even in those policy domains to which the codecision procedure applies if 'co-decisions' should eventually be equally sensitive to preferences of Parliament and Council.

Our arguments are based on very standard spatial voting assumptions and bargaining theory. We made several simplifications that should be relaxed in future research. For example, we did not explicitly analyze the effect of weighted voting in the Council. Also, we considered one isolated instance of bargaining between players who suffered exactly the same disutility from distance to their respective ideal point. Thus, repeated-game effects (typically allowing for a great multiplicity of equilibrium outcomes) and log-rolling based on player-specific utility and / or different distance functions (weighting policy dimensions by subjective measures of salience), were not dealt with. These shortcomings should not be over-estimated, though: True log-rolling complicates the derivation of the contract curve considerably, but the essential bargaining problem of selecting among many Pareto-efficient alternatives (with different distributional consequences) remains the same. Also, regular national and European elections seem to limit the scope for sophisticated repeated-game strategies of EP and CM as such. More controversial is the assumption that Council and Parliament behave like unilateral actors in their negotiations - which is unfortunately very standard, too. This restricts both institutions to exhibit a high level of collective rationality and precludes strategic alliances among individual members of EP and CM.

\section{Appendix}

\section{Proposition 1}

Assume that preferences of EP and CM are represented by utility functions $u_{i}(x) \equiv$ $u\left(d\left(\lambda_{i}, x\right)\right)$ which are strictly decreasing and weakly concave in $d\left(\lambda_{i}, x\right)$ and yield a Pareto frontier described by a function $\phi: u_{\pi}(x) \mapsto \max \left\{u_{\mu}(y): y \in X \wedge u_{\pi}(y)=u_{\pi}(x)\right\}$ which is differentiable on the interior of the contract curve. Then the symmetric Nash bargain $x^{*}(\pi, \mu) \equiv x^{*}$ between EP and CM is closer to the ideal point which is closer to the status quo, i. e.

$$
d(\pi, 0)<d(\mu, 0) \Longleftrightarrow d\left(\pi, x^{*}\right)<d\left(\mu, x^{*}\right),
$$

whenever there are gains from trade.

Proof. Utility is the same concave strictly decreasing function of the distance to the respective status quo for both players. Hence it suffices to show $u_{\pi}^{q}>u_{\mu}^{q} \Longleftrightarrow u_{\pi}^{*}>u_{\mu}^{*}$. Moreover, the Pareto frontier must be symmetric, i. e. $\phi\left(\phi\left(u_{\pi}\right)\right)=\phi\left(u_{\mu}\right)=u_{\pi}$ which implies $\phi^{\prime}\left(\phi\left(u_{\pi}\right)\right) \cdot \phi^{\prime}\left(u_{\pi}\right)=1$ and, in particular,

$$
\phi^{\prime}\left(\tilde{u}_{\pi}\right)=-1
$$


for fixed point $\tilde{u}_{\pi}=\phi\left(\tilde{u}_{\pi}\right)$ (using $\phi^{\prime}\left(u_{\pi}\right)<0$ ). Concavity of utility function $u(\cdot)$ translates into concavity of $\phi(\cdot)$, so (16) implies

$$
\phi^{\prime}\left(u_{\pi}\right) \begin{cases}\geq-1 ; & u_{\pi}<\tilde{u}_{\pi} \\ \leq-1 ; & u_{\pi}>\tilde{u}_{\pi} .\end{cases}
$$

W.l. o. g. let $u_{i}\left(\lambda_{i}\right)=0$ and assume $u_{\pi}^{q}>u_{\mu}^{q}$.

First, consider the case that $u_{\pi}(\mu)<u_{\pi}^{q}$, i. e. CM's ideal point leaves EP worse off than the status quo. The end point of the contract curve preferred by CM then gives exactly utility $u_{\pi}=u_{\pi}^{q}$ to EP, implying that the Nash product $N\left(u_{\pi}, u_{\mu}\right) \equiv\left(u_{\pi}-u_{\pi}^{q}\right)\left(u_{\mu}-u_{\mu}^{q}\right)$ is zero. Since it is positive in the interior of the contract curve, this cannot be the Nash bargaining outcome.

Second, consider the case that $u_{\pi}(\mu) \geq u_{\pi}^{q}$, i. e. CM's ideal point leaves EP weakly better off than the status quo. CM's preferred end point of the contract curve in this case is $\mu$ and yields utility $\phi(\mu)<0$ to $\mathrm{EP}$ and 0 to $\mathrm{CM}$. We show that this is no solution either: The change in the Nash product $N\left(u_{\pi}, u_{\mu}\right)$ implied by moving slightly from $\mu$ towards $\pi$ is captured by its directional derivative at $(\phi(0), 0)$ along the Pareto frontier, i. e. in direction of vector $a \equiv\left(1, \phi^{\prime}(\phi(0))\right)$ :

$$
\begin{aligned}
N_{a}^{\prime}(\phi(0), 0) & =\left(0-u_{\mu}^{q}, \phi(0)-u_{\pi}^{q}\right)\left(\begin{array}{c}
1 \\
\phi^{\prime}(\phi(0))
\end{array}\right) \\
& =-u_{\mu}^{q}+\phi(0) \phi^{\prime}(\phi(0))-u_{\pi}^{q} \phi^{\prime}(\phi(0)) \\
& =-\left(u_{\mu}^{q}+u_{\pi}^{q} \phi^{\prime}(\phi(0))\right)+\phi(0) \phi^{\prime}(\phi(0)) .
\end{aligned}
$$

From $\tilde{u}_{\pi}<0$ follows $\tilde{u}_{\pi}>\phi(0)$, so (17) implies $\left.0 \geq \phi^{\prime}(\phi(0))\right) \geq-1$. Therefore, given $u_{\mu}^{q}<u_{\pi}^{q}<0$, the first summand is strictly positive. Both $\phi(0)$ and $\phi^{\prime}(\phi(0))$ are negative, so the second summand is positive, too. Therefore, $N_{a}^{\prime}(\phi(0), 0)>0$ and $(\phi(0), 0)$ cannot maximize $N(\cdot)$.

It follows that EP and CM must either agree on $\pi$, in which case $u_{\pi}^{*}>u_{\mu}^{*}$ is obvious, or on some point in the interior of the contract curve which is characterized by tangency of an iso- $N(\cdot)$ line and $\phi(\cdot)$ in $\left(u_{\pi}^{*}, u_{\mu}^{*}\right)$. For the latter case, note that the slope of iso- $N(\cdot)$ line

$$
g\left(u_{\pi}\right)=\frac{k}{u_{\pi}-u_{\pi}^{q}}+u_{\mu}^{q}
$$

with $k=\left(u_{\pi}^{*}-u_{\pi}^{q}\right) \cdot\left(u_{\mu}^{*}-u_{\mu}^{q}\right)$ is

$$
g^{\prime}\left(u_{\pi}^{*}\right)=-\frac{u_{\mu}^{*}-u_{\mu}^{q}}{u_{\pi}^{*}-u_{\pi}^{q}}
$$

in $\left(u_{\pi}^{*}, u_{\mu}^{*}\right)$. Suppose $u_{\pi}^{*} \leq u_{\mu}^{*}$. Then $g^{\prime}\left(u_{\pi}^{*}\right)<-1$ given $u_{\pi}^{q}>u_{\mu}^{q}$. However, $u_{\pi}^{*} \leq u_{\mu}^{*}$ means $u_{\pi}^{*} \leq \tilde{u}_{\pi}$, which implies $\phi^{\prime}\left(u_{\pi}\right) \geq-1$ by (17). This is a contradiction, implying that indeed $u_{\pi}^{*}>u_{\mu}^{*}$.

Similarly, assuming $u_{\pi}^{q} \leq u_{\mu}^{q}$ and supposing $u_{\pi}^{*}>u_{\mu}^{*}$ a contradiction can be shown (for any interior solution $g^{\prime}\left(u_{\pi}^{*}\right)>-1$, while (17) implies $\left.\left.\phi^{\prime}\right) u_{\pi}^{*}\right) \leq-1$ ). This establishes the proposition. 


\section{Proposition 2}

Proof. The proof is by complete induction. First, note that the claim is true for $n=1$ and $n=2$ :

$$
x^{*}\left(1, \delta_{\mu}, \delta_{\pi}\right)=\sum_{t=0}^{0}\left(\delta_{\mu} \delta_{\pi}\right)^{t} \cdot \mu^{\prime}=\mu^{\prime}
$$

and

$$
x^{*}\left(2, \delta_{\mu}, \delta_{\pi}\right)=\sum_{t=0}^{0}\left(\delta_{\mu} \delta_{\pi}\right)^{t} \cdot \mu^{\prime}+\sum_{t=0}^{0}\left(\delta_{\mu} \delta_{\pi}\right)^{t} \cdot\left(2 \pi-\delta_{\pi} \pi-\mu^{\prime}\right)=2 \pi-\delta_{\pi} \pi,
$$

in line with above analysis of these cases.

Second, period 2 of the alternating offers bargaining game with $n+2$ periods (also starting with CM's proposal) is strategically equivalent to period 0 of the game with $n$ periods, where in equilibrium $x^{*}\left(n, \delta_{\mu}, \delta_{\pi}\right)$ will be offered by CM and accepted by EP by the induction hypothesis. So in period 1 of the $n+2$-period game, EP optimally proposes $x_{1}=\delta_{\mu} \cdot x^{*}\left(n, \delta_{\mu}, \delta_{\pi}\right)$, making it weakly preferable for CM to accept and obtain (undiscounted) utility $\pi-\left|\pi-\delta_{\mu} x^{*}\left(n, \delta_{\mu}, \delta_{\pi}\right)\right|=2 \pi-\delta_{\mu} x^{*}\left(n, \delta_{\mu}, \delta_{\pi}\right)$ in period 1. In fact, $\left(\delta_{\mu} \cdot x^{*}\left(n, \delta_{\mu}, \delta_{\pi}\right) ; 1\right)$ is the unique $\mathrm{SPE}$ outcome of the subgame of this $n+2$-period game starting with EP's proposal in period 1. Reasoning backwards from this, it is optimal for CM to propose $x^{*}$ with

$$
x^{*}=2 \pi-\delta_{\pi}\left(2 \pi-\delta_{\mu} x^{*}\left(n, \delta_{\mu}, \delta_{\pi}\right)\right)
$$

in period 0 , and for EP to accept - corresponding to the unique SPE outcome $\left(x^{*} ; 0\right)$. Using (8), one can check that

$$
\begin{aligned}
& x^{*}=2 \pi-\delta_{\pi} \cdot 2 \pi \\
& +\delta_{\pi} \delta_{\mu} \cdot \sum_{t=0}^{\left\lfloor\frac{n-1}{2}\right\rfloor}\left(\delta_{\mu} \delta_{\pi}\right)^{t} \cdot \mu^{\prime}+\delta_{\pi} \delta_{\mu} \cdot \sum_{t=0}^{\left\lfloor\frac{n-2}{2}\right\rfloor}\left(\delta_{\mu} \delta_{\pi}\right)^{t} \cdot\left(2 \pi-\delta_{\pi} \pi-\mu^{\prime}\right)-\delta_{\pi} \delta_{\mu} \cdot \sum_{t=0}^{\left\lfloor\frac{n-3}{2}\right\rfloor} \delta_{\pi} \cdot\left(\delta_{\mu} \delta_{\pi}\right)^{t} \cdot \pi \\
& =\left(2 \pi-\delta_{\pi} \pi\right)-\delta_{\pi} \pi \\
& +\sum_{t=1}^{\left\lfloor\frac{(n+2)-1}{2}\right\rfloor}\left(\delta_{\mu} \delta_{\pi}\right)^{t} \cdot \mu^{\prime}+\mu^{\prime}+\sum_{t=1}^{\left\lfloor\frac{(n+2)-2}{2}\right\rfloor}\left(\delta_{\mu} \delta_{\pi}\right)^{t} \cdot\left(2 \pi-\delta_{\pi} \pi-\mu^{\prime}\right)-\mu^{\prime}-\sum_{t=1}^{\left\lfloor\frac{(n+2)-3}{2}\right\rfloor} \delta_{\pi} \cdot\left(\delta_{\mu} \delta_{\pi}\right)^{t} \cdot \pi \\
& =\sum_{t=0}^{\left\lfloor\frac{(n+2)-1}{2}\right\rfloor}\left(\delta_{\mu} \delta_{\pi}\right)^{t} \cdot \mu^{\prime}+\sum_{t=0}^{\left\lfloor\frac{(n+2)-2}{2}\right\rfloor}\left(\delta_{\mu} \delta_{\pi}\right)^{t} \cdot\left(2 \pi-\delta_{\pi} \pi-\mu^{\prime}\right)-\sum_{t=0}^{\left\lfloor\frac{(n+2)-3}{2}\right\rfloor} \delta_{\pi} \cdot\left(\delta_{\mu} \delta_{\pi}\right)^{t} \cdot \pi \\
& =x^{*}\left(n+2, \delta_{\mu}, \delta_{\pi}\right) .
\end{aligned}
$$

Thus, since the claim is true for $n=1$ and $n=2$, it must be true for all $n \geq 1$.

\section{References}

Bade, S. (2002), Multidimensional Voting under Uncertainty, New York University, mimeo. 
Binmore, K. G. (1987), Nash bargaining theory II, In K. G. Binmore and P. Dasgupta (Eds.), The Economics of Bargaining, pp. 61-76, Oxford.

Binmore, K.G., M. Piccione, and L. Samuelson (1998), Evolutionary stability in alternatingoffers bargaining games, Journal of Economic Theory 80, pp. 257-291.

Bornstein, G., and Yaniv, I. (1998), Individual and group behavior in the ultimatum game: Are groups more rational players? Experimental Economics 1, pp. 101-8

Chae, S., and P. Heidhues (2002), Bargaining between groups, WZB Discussion Paper, Berlin.

Crombez, C. (1997), The codecision procedure of the European Union, Legislative Studies Quarterly 22, 97-119.

Crombez (2000), The institutional reform and codecision in the European Union, Constitutional Political Economy 11, 41-57.

Crombez, C., Steunenberg, B. and Corbett, R. (2000), Understanding the EU legislative process: political scientists and practitioners' perspectives, European Union Politics 1, 363-381.

Edgeworth, F. Y. (1881), Mathematical Psychics: An Essay on the Application of Mathematics to the Moral Sciences, Reprinted by A. M. Kelley, New York, 1961.

Fehr, E., and S. Gächter (2002), Altruistic Punishment in Humans, Nature 415 (January 10), pp. 137-140.

Fehr, E., and K. Schmidt (2001), Theories of Fairness and Reciprocity - Evidence and Economic Applications, forthcoming in M. Dewatripont, L. Hansen and St. Turnovsky (eds.), Advances in Economics and Econometrics - 8th World Congress, Econometric Society Monographs.

Fudenberg, D., and D.K. Levine (1998), The Theory of Learning in Games, Cambridge, MA: MIT Press.

Gale, J., K. G. Binmore, and L. Samuelson (1995), Learning to be imperfect: The ultimatum game, Games and Economic Behavior 8, pp. 56-90.

Garrett, G. (1995), From the Luxembourg compromise to codecision: decision making in the European Union, Electoral Studies 50, 269-299.

Garrett, G., Tsebelis, G. and Corbett, R. (2001), The EU legislative process: academics vs. pratitioners - round 2, European Union Politics 2, 353-366.

Van Bragt, D. D. B., E. H. Gerding, and J. A. La Poutré (2000), Equilibrium selection in alternating-offers bargaining models - The evolutionary computing approach. Report SEN-R0013, Stichting Mathematisch Centrum, Amsterdam.

Güth, W. (1995), On ultimatum bargaining experiments - A personal review, Journal of Economic Behavior and Organization 27, pp. 329-344. 
Harsanyi, J.C. (1956), Approaches to the Bargaining Problem Before and After the Theory of Games: A Critical Discussion of Zeuthen's, Hicks', and Nash's Theories, Econometrica 24, pp. 144-157.

Holler, M.J., and G. Owen (2001), Power Indices and Coalition Formation, Dordrecht: Kluwer.

Kalai, E. (1977), Nonsymmetric Nash solutions and replications of 2-person bargaining, International Journal of Game Theory 6, pp. 129-133.

Kocher, M. G. and Sutter, M. (2002), The decision maker matters. Individual versus team behavior in experimental beauty-contest games. Institute of Public Economics. Discussion Paper 2000/4. University of Innsbruck; revised version January 2002.

Muthoo, A. (1999), Bargaining Theory with Applications, Cambridge.

Napel, S. (2002), Bilateral Bargaining: Theory and Applications, Lecture Notes in Economics and Mathematical Systems 518, Heidelberg.

Napel, S. (2003), Aspiration Adaptation in the Ultimatum Minigame, Games and Economic Behavior 43, pp. 86-106.

Napel, S., and M. Widgrén (2002), Power Measurement as Sensitivity Analysis - A Unified Approach, University of Bielefeld, Institute of Mathematical Economics, Working Paper No. 345.

Napel, S., and M. Widgrén (2003), Strategic power in EU codecision, mimeo.

Nash, J. F. (1950), The bargaining problem, Econometrica 18, pp. 155-162.

Nash, J. F. (1953), Two-person cooperative bargaining games, Econometrica 21, pp. 128140.

Nurmi, H. (1998), Rational Behaviour and Design of Institutions, Cheltenham: Edward Elgar.

Osborne, M. J. and A. Rubinstein (1990), Bargaining and Markets, San Diego, CA.

Roth, A. E. (1995), Bargaining experiments, In J. Kagel and A. E. Roth (Eds.), Handbook of Experimental Economics, Chapter 4, pp. 253-348, Princeton, NJ.

Roth, A.E., and I. Erev (1995), Learning in Extensive-Form Games: Experimental Data and Simple Dynamic Models of the Intermediate Term, Games and Economic Behavior 8, pp. 164-212.

Rusinowska, A. (2002), On certain generalization of Rubinstein's bargaining model, In: L.A. Petrosjan and V.V. Mazalov (eds.), Game Theory and Applications, Vol. 8, Hauppauge, NY: Nova Science Publishers.

Rubinstein, A. (1982), Perfect equilibrium in a bargaining model, Econometrica 50, pp. 97109.

Slonim, R. and Roth, A.E. (1998), Learning in High Stakes Ultimatum Games: An Experiment in the Slovak Republic, Econometrica 66, pp. 569-596. 
Steunenberg, B. (1994). Decision-Making under Different Institutional Arrangements: Legislation by the European Community, Journal of Theoretical and Institutional Economics 150: 642-669.

Steunenberg, B., and Dimitrova (1999), Interests, Legitimacy and Constitutional Choice: the Extension of the Codecision Procedure in Amsterdam, University of Twente, mimeo.

Steunenberg, B., and T. Selck (2002), The insignificance of the significance? A review of procedural models on EU decision making, University of Leiden, mimeo.

Steunenberg, B., Schmidtchen, D. and Koboldt, C. (1999), Strategic Power in the European Union: Evaluating the Distribution of Power in Policy Games, Journal of Theoretical Politics 11: 339-366.

Tsebelis, G., and Garrett, G. (2000), Legislative politics in the European Union, European Union Politics 1, 5-32.

Tsebelis, G., and Money (1997), Bicameralism, Cambridge University Press, Cambridge.

Weibull, J.W. (1995), Evolutionary Game Theory, Cambridge, MA: MIT Press.

Young, H. P. (1993), An evolutionary model of bargaining, Journal of Economic Theory 59, pp. $145-168$. 


\section{CESifo Working Paper Series}

(for full list see www.cesifo.de)

963 Jakob de Haan, Jan-Egbert Sturm and Bjørn Volkerink, How to Measure the Tax Burden on Labour at the Macro-Level?, June 2003

964 Harry Grubert, The Tax Burden on Cross-Border Investment: Company Strategies and Country Responses, June 2003

965 Kirk A. Collins and James B. Davies, Measuring Effective Tax Rates on Human Capital: Methodology and an Application to Canada, June 2003

966 W. Steven Clark, Using Micro-Data to Assess Average Tax Rates, June 2003

967 Christopher Heady, The 'Taxing Wages' Approach to Measuring the Tax Burden on Labour, June 2003

968 Michael P. Devereux and Alexander Klemm, Measuring Taxes on Income from Capital: Evidence from the UK, June 2003

969 Bernhard Eckwert and Itzhak Zilcha, The Effect of Better Information on Income Inequality, June 2003

970 Hartmut Egger and Josef Falkinger, The Role of Public Infrastructure for Firm Location and International Outsourcing, June 2003

971 Dag Morten Dalen and Trond E. Olsen, Regulatory Competition and Multi-national Banking, June 2003

972 Matthias Wrede, Tax Deductibility of Commuting Expenses and Residential Land Use with more than one Center, June 2003

973 Alessandro Cigno and Annalisa Luporini, Scholarships or Student Loans? Subsidizing Higher Education in the Presence of Moral Hazard, June 2003

974 Chang Woon Nam, Andrea Gebauer and Rüdiger Parsche, Is the Completion of EU Single Market Hindered by VAT Evasion?, June 2003

975 Michael Braulke and Giacomo Corneo, Capital Taxation May Survive in Open Economies, July 2003

976 Assar Lindbeck, An Essay on Welfare State Dynamics, July 2003

977 Henrik Jordahl and Luca Micheletto, Optimal Utilitarian Taxation and Horizontal Equity, July 2003 
978 Martin D. D. Evans and Richard K. Lyons, Are Different-Currency Assets Imperfect Substitutes?, July 2003

979 Thorsten Bayindir-Upmann and Frank Stähler, Market Entry Regulation and International Competition, July 2003

980 Vivek Ghosal, Firm and Establishment Volatility: The Role of Sunk Costs, Profit Uncertainty and Technological Change, July 2003

981 Christopher A. Pissarides, Unemployment in Britain: A European Success Story, July 2003

982 Wolfgang Buchholz, Richard Cornes, and Wolfgang Peters, On the Frequency of Interior Cournot-Nash Equilibria in a Public Good Economy, July 2003

983 Syed M. Ahsan and Panagiotis Tsigaris, Choice of Tax Base Revisited: Cash Flow vs. Prepayment Approaches to Consumption Taxation, July 2003

984 Campbell Leith and Jim Malley, A Sectoral Analysis of Price-Setting Behavior in US Manufacturing Industries, July 2003

985 Hyun Park and Apostolis Philippopoulos, Choosing Club Membership under Tax Competition and Free Riding, July 2003

986 Federico Etro, Globalization and Political Geography, July 2003

987 Dan Ariely, Axel Ockenfels and Alvin E. Roth, An Experimental Analysis of Ending Rules in Internet Auctions, July 2003

988 Paola Conconi and Carlo Perroni, Self-Enforcing International Agreements and Domestic Policy Credibility, July 2003

989 Charles B. Blankart and Christian Kirchner, The Deadlock of the EU Budget: An Economic Analysis of Ways In and Ways Out, July 2003

990 M. Hasham Pesaran and Allan Timmermann, Small Sample Properties of Forecasts from Autoregressive Models under Structural Breaks, July 2003

991 Hyun Park, Apostolis Philippopoulos and Vangelis Vassilatos, On the Optimal Size of Public Sector under Rent-Seeking competition from State Coffers, July 2003

992 Axel Ockenfels and Alvin E. Roth, Late and Multiple Bidding in Second Price Internet Auctions: Theory and Evidence Concerning Different Rules for Ending an Auction, July 2003

993 Pierre Salmon, The Assignment of Powers in an Open-ended European Union, July 2003

994 Louis N. Christofides and Chen Peng, Contract Duration and Indexation in a Period of Real and Nominal Uncertainty, July 2003 
995 M. Hashem Pesaran, Til Schuermann, Björn-Jakob Treutler, and Scott M. Weiner, Macroeconomic Dynamics and Credit Risk: A Global Perspective, July 2003

996 Massimo Bordignon and Sandro Brusco, On Enhanced Cooperation, July 2003

997 David F. Bradford, Addressing the Transfer-Pricing Problem in an Origin-Basis X Tax, July 2003

998 Daniel Gros, Who Needs Foreign Banks?, July 2003

999 Wolfram Merzyn and Heinrich W. Ursprung, Voter Support for Privatizing Education: Evidence on Self-Interest and Ideology, July 2003

1000 Jo Thori Lind, Fractionalization and the Size of Government, July 2003

1001 Daniel Friedman and Donald Wittman, Litigation with Symmetric Bargaining and TwoSided Incomplete Information, July 2003

1002 Matthew Clarke and Sardar M. N. Islam, Health Adjusted GDP (HAGDP) Measures of the Relationship Between Economic Growth, Health Outcomes and Social Welfare, July 2003

1003 Volker Grossmann, Contest for Attention in a Quality-Ladder Model of Endogenous Growth, August 2003

1004 Marcel Gérard and Joan Martens Weiner, Cross-Border Loss Offset and Formulary Apportionment: How do they affect multijurisdictional firm investment spending and interjurisdictional tax competition?, August 2003

1005 Burkhard Heer, Nonsuperneutrality of Money in the Sidrauski Model with Heterogeous Agents, August 2003

1006 V. Anton Muscatelli, Piergiovanna Natale, and Patrizio Tirelli, A Simple and Flexible Alternative to the Stability and Growth Pact Deficit Ceilings. Is it at hand?, August 2003

1007 Reto Foellmi and Josef Zweimüller, Inequality and Economic Growth: European Versus U.S. Experiences, August 2003

1008 James S. Costain and Michael Reiter, Business Cycles, Unemployment Insurance, and the Calibration of Matching Models, August 2003

1009 Marco Runkel, Optimal Contest Design when the Designer's Payoff Depends on Competitive Balance, August 2003

1010 Donald O. Parsons, Torben Tranaes and Helene Bie Lilleør, Voluntary Public Unemployment Insurance, August 2003

1011 Rüdiger Pethig and Andreas Wagener, Profit Tax Competition and Formula Apportionment, August 2003 
1012 Johan Willner, Privatisation and Public Ownership in Finland, August 2003

1013 Seppo Kari and Jouko Ylä-Liedenpohja, Taxation and Valuation of International Real Investments, August 2003

1014 James Heckman, Rosa Matzkin and Lars Nesheim, Simulation and Estimation of Hedonic Models, August 2003

1015 Biswa N. Bhattacharyay, Towards a Macro-Prudential Leading Indicators Framework for Monitoring Financial Vulnerability, August 2003

1016 J. Stephen Ferris and Stanley L. Winer, Searching for Keynes: With Application to Canada, 1870-2000, August 2003

1017 Massimo Bordignon, Luca Colombo and Umberto Galmarini, Fiscal Federalism and Endogenous Lobbies' Formation, August 2003

1018 Annette Alstadsæter, The Dual Income Tax and Firms'Income Shifting through the Choice of Organizational Form and Real Capital Investments, August 2003

1019 Peter Fredriksson and Bertil Holmlund, Optimal Unemployment Insurance Design: Time Limits, Monitoring, or Workfare?, August 2003

1020 Kashif S. Mansori, Following in their Footsteps: Comparing Interest Parity Conditions in Central European Economies to the Euro Countries, August 2003

1021 Christoph Borgmann and Matthias Heidler, Demographics and Volatile Social Security Wealth: Political Risks of Benefit Rule Changes in Germany, August 2003

1022 Kjell Erik Lommerud, Bjørn Sandvik and Odd Rune Staume, Good Jobs, Bad Jobs and Redistribution, August 2003

1023 Patrick Karl O'Brien, The Governance of Globalization: The Political Economy of Anglo-American Hegemony, 1793-2003, September 2003

1024 Antonio Ciccone and Giovanni Peri, Skills' Substitutability and Technological Progress: U.S. States 1950-1990, September 2003

1025 Bjørn Sandvik, Optimal Taxation and Normalisations, September 2003

1026 Massimo Bordignon and Gilberto Turati, Bailing Out Expectations and Health Expenditure in Italy, September 2003

1027 José A. Herce, Namkee Ahn, Ricard Génova, and Joaquín Pereira, Bio-Demographic and Health Aspects of Ageing in the EU, September 2003

1028 John Komlos and Marieluise Baur, From the Tallest to (One of) the Fattest: The Enigmatic Fate of the American Population in the $20^{\text {th }}$ Century, September 2003

1029 Stefan Napel and Mika Widgrén, Bargaining and Distribution of Power in the EU's Conciliation Committee, September 2003 